\title{
Multifunctional Two-Dimensional Conjugated Materials for Dopant-Free Perovskite Solar Cells with Efficiency Exceeding 22\%
}

Qiang Fu, ${ }^{1, t}$ Zhiyuan Xu, ${ }^{1,+}$ Xingchen Tang, ${ }^{1}$ Tingting Liu, ${ }^{1}$ Xiyue Dong, ${ }^{1}$ Xiaodan Zhang, ${ }^{2,4}$ Nan Zheng, ${ }^{3}$ Zengqi Xie, ${ }^{3}$ and Yongsheng Liu'1,4, *

${ }^{1}$ The Centre of Nanoscale Science and Technology and Key Laboratory of Functional Polymer Materials, Institute of Polymer Chemistry, College of Chemistry, Nankai University, Tianjin 300071, China.

${ }^{2}$ Institute of Photoelectronic Thin Film Devices and Technology, Nankai University, Tianjin 300071, China.

${ }^{3}$ Institute of Polymer Optoelectronic Materials and Devices, State Key Laboratory of Luminescent Materials and Devices, South China University of Technology, Guangzhou 510640, China.

${ }^{4}$ Renewable Energy Conversion and Storage Center, Nankai University, Tianjin 300071, China

*Correspondence: liuys@nankai.edu.cn 


\section{Materials}

The reactions and manipulations were carried out under a nitrogen atmosphere with the use of standard Schlenk techniques. All the chemicals were purchased from commercial businesses and without further purification and the solvents were treated according to the standard procedures. The DPP derivatives, such as DPP and Br-DPP, were synthesized according to the previous literature procedures. ${ }^{1-2}$

\section{Measurements}

Matrix-assisted laser desorption/ionization time-of-flight mass spectrometry (MALDI-TOF MS) was performed on a Bruker Autoflex III TOF/TOF200. The Fourier-transform infrared spectroscopy (FTIR) spectra (KBr) were recorded on a Bruker Tensor 27 Infrared spectroscope in transmission mode. FTIR data are reported with a wavenumber $\left(\mathrm{cm}^{-1}\right)$ scale. Powder X-ray diffraction (XRD) measurements were carried out by using Rigaku Ultima IV X-ray powder diffractometer with $\mathrm{Cu} \mathrm{K} \alpha$ radiation $(\lambda=1.54056 \AA)$ over the range of $2 \theta=2.1-30.0^{\circ}$ with a step size of $0.02^{\circ}$ and $0.4 \mathrm{~s}$ per step. Thermogravimetric analysis (TGA) was performed on a NETZSCH STA 409PC instrument by heating the 2DP-TDB at $10{ }^{\circ} \mathrm{C} \min ^{-1}$ to $800{ }^{\circ} \mathrm{C}$ under argon. UV-Vis-NIR absorption spectra were measured on a Cary 5000 UV-Visible-NIR S3 spectrophotometer. The sample films were deposited on the quartz plate. Scanning electron microscopy (SEM) images were obtained using the ZEISS MERLIN Compact. HighResolution Transmission electron microscopy (HRTEM) images were recorded on a JEM2100 transmission electron microscope with an accelerating voltage of $200 \mathrm{kV}$. Steady-state photoluminescence (PL) and time-resolved photoluminescence (TRPL) were measured via a 
Spectrofluorometer FS5 (Edinburgh Instruments Ltd.) with excitation at $450 \mathrm{~nm}$. The perovskite films were deposited on nonconductive glasses. Water contact angles were measured using a JC2000D1 contact angle instrument. The solubility of 2DP-TDB was measured by preparing supersaturated 2DP-TDB solutions in various solvents and weighed the mass of 2DPTDB solid through removing a certain volume of the upper clear liquid.

2.1 Nuclear magnetic resonance (NMR)

The ${ }^{1} \mathrm{H}$ and ${ }^{13} \mathrm{C}$ NMR spectra were recorded using a Bruker AV400 Spectrometer in solution at $400 \mathrm{MHz}$ and $101 \mathrm{MHz}$, respectively. Proton $\left({ }^{1} \mathrm{H}\right) \mathrm{NMR}$ information is given in the following format: multiplicity (s, singlet; d, doublet; t, triplet; q, quartet; qui, quintet; sept, septet; m, multiplet), coupling constant(s) $(\mathrm{J})$ in Hertz $(\mathrm{Hz})$, the number of protons. Carbon $\left({ }^{13} \mathrm{C}\right) \mathrm{NMR}$ spectra are reported in ppm $(\delta)$ relative to residual $\mathrm{CDCl}_{3}(\delta 77.00)$.

\subsection{Gel permeation chromatography (GPC)}

The molar mass and its distribution for the 2DP-TDB were determined by gel permeation chromatography on a Waters 1525 system. Tetrahydrofuran (THF) was used as the mobile phase $\left(1 \mathrm{~mL} \mathrm{~min}^{-1}\right)$, and polystyrene was used as the standard in the calibration of the molar masses.

\subsection{Electrochemical cyclic voltammogram}

Cyclic voltammetry (CV) experiment was performed with a CHI600E electrochemical workstation with a conventional three-electrode configuration employing a glassy carbon electrode as the working electrode, a saturated calomel electrode (SCE) as the reference electrode, and a Pt wire as the counter electrode. CV measurement was carried out at room temperature in a $0.1 \mathrm{~mol} \mathrm{~L}^{-1}$ tetrabutylammonium hexafluorophosphate $\left(\mathrm{Bu}_{4} \mathrm{NPF}_{6}\right)$ acetonitrile 
solution, and the scan rate was $100 \mathrm{mV} \mathrm{s}^{-1}$. The half potential of Ferrocene in this condition is $0.4 \mathrm{~V}$. Using versatile calculation formula that assuming the absolute energy level of $\mathrm{FeCp}^{2+} / 0$ to be $4.8 \mathrm{eV}$ below vacuum:

$$
\mathrm{E}_{\mathrm{HOMO}}=-\mathrm{e}\left[\mathrm{E}_{\mathrm{ox}}+\left(4.8-\mathrm{E}_{\mathrm{Fc}}\right)\right] \mathrm{eV} ; \mathrm{E}_{\mathrm{LUMO}}=-\mathrm{e}\left[\mathrm{E}_{\mathrm{red}}+\left(4.8-\mathrm{E}_{\mathrm{Fc}}\right)\right] \mathrm{eV} .3,4
$$

\subsection{Grazing-Incidence Wide-Angle X-ray Scattering (GIWAXS)}

GIWAXS measurement was performed at MetalJet-D2 Excillum on the wavelength of $0.134144 \mathrm{~nm}$ with Xeuss 2.0. The 2DP-TDB film was deposited on the silicon and was irradiated at a fixed X-ray incident angle of $0.2^{\circ}$ with an exposure time of $1800 \mathrm{~s}$.

\subsection{Space-charge-limited-current (SCLC) mobility measurement}

The hole mobility was measured using the space charge limited current (SCLC) method, employing a diode configuration of ITO/PEDOT:PSS/2DP-TDB/Au for hole by taking the dark current density in the range of $0-10 \mathrm{~V}$. The results were fitted to a space charge limited form, where the SCLC is described by $J=\frac{9 \varepsilon_{0} \varepsilon_{r} \mu_{h} V^{2}}{8 L^{3}}$ where $\mathrm{J}$ is the current density, $\mathrm{L}$ is the film thickness of the active layer, $\mu_{\mathrm{h}}$ is the hole mobility, $\varepsilon_{\mathrm{r}}$ is the relative dielectric constant of the transport medium, $\varepsilon_{0}$ is the permittivity of free space $\left(8.85 \times 10^{-12} \mathrm{~F} \mathrm{~m}^{-1}\right), \mathrm{V}$ is the internal voltage in the device. The 2DP-TDB film thickness was $127 \mathrm{~nm}$ measured using Dektak 150 surface profilometer for the hole and electron mobility tests. 2DP-TDB solution ( $8 \mathrm{mg} \mathrm{mL}^{-1}$ in chlorobenzene) was spin-coated onto ITO/PEDOT:PSS substrate at $500 \mathrm{rpm}$ for $10 \mathrm{~s}$ and $1000 \mathrm{rpm}$ for $60 \mathrm{~s}$.

2.6 Conventional perovskite photovoltaic device fabrication.

The ITO substrate was sequentially cleaned with distilled water, acetone, and isopropyl alcohol. The $\mathrm{SnO}_{2}$ electron transport layer was coated onto the ITO substrate and annealed at $150{ }^{\circ} \mathrm{C}$ for 
30 min in air. After being cooled to room temperature, the substrate was treated with UV-ozone for $10 \mathrm{~min}$ before spin-coating of perovskite solution. Typically, $\mathrm{PbI}_{2}$ was dissolved in $\mathrm{DMF} / \mathrm{DMSO}(\mathrm{v} / \mathrm{v}, 94 / 6)$ at a concentration of $1.5 \mathrm{M}$, followed by stirring at $70^{\circ} \mathrm{C}$ for $15 \mathrm{~h}$. The $\mathrm{PbI}_{2}$ solution then was deposited by spin coating at $1900 \mathrm{rpm}$ for $30 \mathrm{~s}$, dried at $70{ }^{\circ} \mathrm{C}$ for $1 \mathrm{~min}$, and cooled to room temperature. A solution of FAI/MAI/MACl $\left(76.5: 13.5: 18 \mathrm{mg} \mathrm{mL}^{-1}\right)$ in isopropanol was spin-coated on the top of the $\mathrm{PbI}_{2}$ layer at a spin-speed of $2500 \mathrm{rpm}$ for $40 \mathrm{~s}$, followed by thermal annealing at $160{ }^{\circ} \mathrm{C}$ for $10 \mathrm{~min}$ in the air (relative humidity $\sim 40 \%$ ). After being cooled to room temperature, 2DP-TDB solution ( $7 \mathrm{mg} / \mathrm{mL}$ in chloroform) was spincoated on the perovskite film at $2000 \mathrm{rpm}$ or TB-DPP solution $(14 \mathrm{mg} / \mathrm{mL}$ in chloroform) was spin-coated on the perovskite film at $8000 \mathrm{rpm}$. Finally, a $15 \mathrm{~nm} \mathrm{MoO}$ layer and $80 \mathrm{~nm} \mathrm{Ag}$ layer were deposited by thermal evaporation under a pressure of $1.0 \times 10^{-4} \mathrm{~Pa}$. The effective area was $0.1 \mathrm{~cm}^{2}$ defined by a mask.

2.7 Optimized perovskite photovoltaic device with 4-fluorobenzamide hydrochloride (pFPhFACl).

The ITO substrate was sequentially cleaned with distilled water, acetone, and isopropyl alcohol. The $\mathrm{SnO}_{2}$ electron transport layer was coated onto ITO substrate and annealed at $150{ }^{\circ} \mathrm{C}$ for 30 min in air. After being cooled to room temperature, the substrate was treated with UV-ozone for $10 \mathrm{~min}$ before spin-coating of perovskite solution. Typically, $\mathrm{PbI}_{2}$ was dissolved in $\mathrm{DMF} / \mathrm{DMSO}(\mathrm{v} / \mathrm{v}, 94 / 6)$ at a concentration of $1.5 \mathrm{M}$, followed by stirring at $70{ }^{\circ} \mathrm{C}$ for $15 \mathrm{~h}$. The $\mathrm{PbI}_{2}$ solution then was deposited by spin coating at $1900 \mathrm{rpm}$ for $30 \mathrm{~s}$, dried at $70{ }^{\circ} \mathrm{C}$ for $1 \mathrm{~min}$, and cooled to room temperature. A solution of $\mathrm{FAI} / \mathrm{MAI} / \mathrm{MACl} / \mathrm{p}-\mathrm{FPhFACl}(76.5: 13.5: 18: 3$ $\mathrm{mg} \mathrm{mL} \mathrm{m}^{-1}$ ) in isopropanol was spin-coated on the top of the $\mathrm{PbI}_{2}$ layer at a spin-speed of 2500 
rpm for $40 \mathrm{~s}$, followed by thermal annealing at $160{ }^{\circ} \mathrm{C}$ for $12 \mathrm{~min}$ in the air (relative humidity $\sim 40 \%$ ). After being cooled to room temperature, 2DP-TDB solution (7 mg/mL in chloroform) was spin-coated on the perovskite film at $2000 \mathrm{rpm}$. Finally, a $15 \mathrm{~nm} \mathrm{MoO}$ layer and $80 \mathrm{~nm}$ Ag layer were deposited by thermal evaporation under a pressure of $1.0 \times 10^{-4} \mathrm{~Pa}$. The effective area was $0.1 \mathrm{~cm}^{2}$ defined by a mask.

\subsection{TPV and TPC}

A white light bias was generated from an array of diodes (Molex 180081-4320) with a light intensity of about 0.5 sun. A diode pumped laser (Lapa-80) was used as the perturbation source, with a pulse duration of $10 \mathrm{~ns}$ and a repetition frequency of $20 \mathrm{~Hz}$. The perturbation light intensity was attenuated to keep the amplitude of transient VOC $(\triangle \mathrm{VOC})$ below $10 \mathrm{mV}$ so that $\triangle$ VOC $<<$ VOC. Voltage and current dynamics were recorded on a digital oscilloscope (Tektronix MDO4104C), and voltages at open circuit and currents under short circuit conditions were measured over a $1 \mathrm{M} \Omega$ and a $50 \Omega$ resistor, respectively.

\subsection{Trap density and mobility measurements}

The trap-state density $\mathrm{N}_{\mathrm{t}}$ of control and target perovskite films with different HTMs were measured by space-charge-limited-current (SCLC) method using a diode configuration of ITO/PEDOT:PSS/Perovskite/HTMs/Ag for hole by taking the dark current density in the range of 0-8 V and fitting the S4 results to a space charge limited form, where the $\mathrm{N}_{\mathrm{t}}$ was calculated according to the relation:

$$
N_{t}=\frac{2 \mathrm{~V}^{\mathrm{TFL}} \varepsilon_{0} \varepsilon_{\mathrm{r}}}{\mathrm{e} L^{2}}
$$

where $\mathrm{V}_{\mathrm{TFL}}$ is the trap-filled limit voltage, $\varepsilon_{0}$ is the vacuum permittivity $\left(\varepsilon_{0}=8.854 \times 10^{-12} \mathrm{~F} / \mathrm{m}\right)$, 
and $\mathrm{e}$ is the electron charge $\left(\mathrm{e}=1.6 \times 10^{-19} \mathrm{C}\right), \mathrm{L}$ is the thickness of the perovskite film $(\mathrm{L}=730$ $\mathrm{nm})$, and adopting $\varepsilon_{\mathrm{r}}$ of 28.8 .

\subsection{X-ray photoelectron spectroscopy measurements}

X-ray photoelectron spectroscopy was performed on Thermo ESCALAB 250XI. The thickness of HTLs was below $10 \mathrm{~nm}$ for XPS studies because these thinner films allowed us to probe the $\mathrm{FA}_{0.85} \mathrm{MA}_{0.15} \mathrm{PbI}_{3} / \mathrm{HTL}$ interface more easily. The pristine 2DP-TDB and TB-DPP thin films use glass as substrates. The perovskite film and the perovskite film/HTLs use glass $/ \mathrm{ITO} / \mathrm{SnO}_{2}$ as substrates.

3. Synthetic procedures<smiles>Brc1cc(Br)cc(Br)c1</smiles>

1

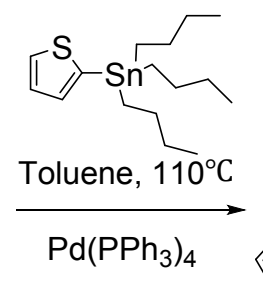

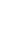<smiles>c1csc(-c2cc(-c3cccs3)cc(-c3cccs3)c2)c1</smiles>

TB
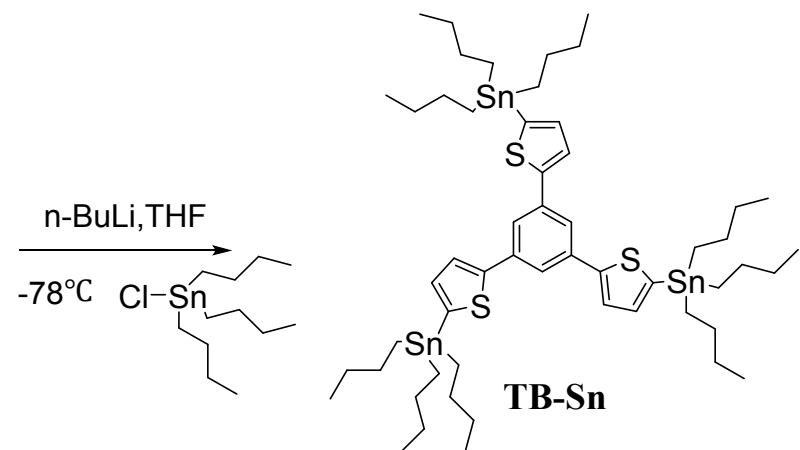

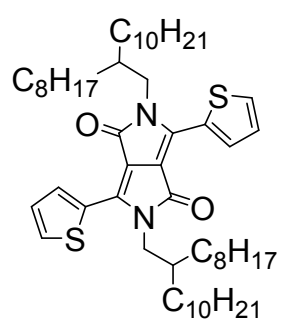

DPP

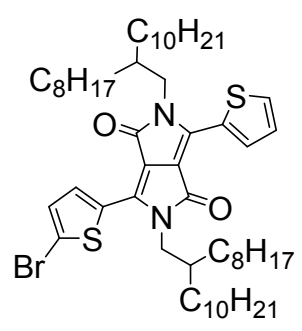

Br-DPP

Scheme S1. Synthesis routes of the important intermediates TB-Sn, DPP-Br.

1) Synthesis of TB

$\mathrm{Pd}\left(\mathrm{PPh}_{3}\right)_{4}(184 \mathrm{mg}, 0.159 \mathrm{mmol})$ was added to a solution of compound $1(1.0 \mathrm{~g}, 3.18 \mathrm{mmol})$ and 2-(tributylstannyl)thiophene $(4.2 \mathrm{~g}, 11.13 \mathrm{mmol})$ in toluene $(40 \mathrm{~mL})$ under nitrogen. After 
being stirred at $110{ }^{\circ} \mathrm{C}$ for 24 hours, the reaction mixture was poured into water and extracted with dichloromethane. The organic layer was washed with water and then dried over $\mathrm{Na}_{2} \mathrm{SO}_{4}$. After removal of the solvent, the crude product was purified by column chromatography on silica gel using hexane as eluant to afford TB (0.89 g, 86\%) as a white solid. ${ }^{1} \mathrm{H}$ NMR (400 $\mathrm{MHz}, \mathrm{CDCl} 3) \delta 7.75(\mathrm{~s}, 3 \mathrm{H}), 7.42(\mathrm{dd}, \mathrm{J}=3.6,1.1 \mathrm{~Hz}, 3 \mathrm{H}), 7.34(\mathrm{dd}, \mathrm{J}=5.1,1.0 \mathrm{~Hz}, 3 \mathrm{H}), 7.13$ $(\mathrm{dd}, \mathrm{J}=5.1,3.6 \mathrm{~Hz}, 3 \mathrm{H}) .{ }^{13} \mathrm{C} \mathrm{NMR}(101 \mathrm{MHz}, \mathrm{CDCl} 3) \delta(\mathrm{ppm}): 143.46,135.62,128.04,125.31$, $123.80,122.66$.

\section{2) Synthesis of TB-Sn}

The n-butyllithium (n-BuLi) $(7.7 \mathrm{~mL}, 12.30 \mathrm{mmol})$ in hexanes was added dropwise into a solution of TB (400 mg, $1.23 \mathrm{mmol})$ in anhydrous THF $(40 \mathrm{~mL})$ in $-78^{\circ} \mathrm{C}$ under nitrogen. The reaction was stirred at $-78{ }^{\circ} \mathrm{C}$ for $1 \mathrm{~h}$ and then warmed to room temperature for another 2 hours. Chlorotributyltin $(3.4 \mathrm{~mL}, 12.55 \mathrm{mmol})$ was added into the system quickly, and the reaction was stirred at room temperature for another $12 \mathrm{~h}$. The reaction mixture was poured into water and extracted with hexane. The organic layer was washed with water and then dried over $\mathrm{Na}_{2} \mathrm{SO}_{4}$. After removal of the solvent, the crude product was purified by column chromatography on silica gel (soaked by triethylamine) using hexane as eluant to afford TB-Sn as a colorless oil $(0.95 \mathrm{~g}, 65 \%) .{ }^{1} \mathrm{H}$ NMR $\left(400 \mathrm{MHz}, \mathrm{CDCl}_{3}\right) \delta 7.74(\mathrm{~s}, 3 \mathrm{H}), 7.52(\mathrm{~d}, \mathrm{~J}=3.3 \mathrm{~Hz}$, 3H), $7.17(\mathrm{~d}, \mathrm{~J}=3.3 \mathrm{~Hz}, 3 \mathrm{H}), 1.64-1.58(\mathrm{~m}, 18 \mathrm{H}), 1.37-1.31(\mathrm{q}, \mathrm{J}=7.3 \mathrm{~Hz}, 18 \mathrm{H}), 1.17-$ $1.11(\mathrm{~m}, 18 \mathrm{H}), 0.91(\mathrm{~m}, 27 \mathrm{H}) .{ }^{13} \mathrm{C}$ NMR $(101 \mathrm{MHz}, \mathrm{CDCl} 3) \delta 148.41,136.37,135.38,134.63$, $123.86,121.48,27.96,26.26,12.65,9.86$.

3) Synthesis of Br-DPP

N-Bromosuccinimide $(285 \mathrm{mg}, 1.60 \mathrm{mmol})$ was added to a solution of compound DPP $(1.38 \mathrm{~g}$, 
$1.60 \mathrm{mmol}$ ) in anhydrous $\mathrm{CHCl}_{3}$ at $0{ }^{\circ} \mathrm{C}$. After being stirred for $12 \mathrm{~h}$ at room temperature in dark, the reaction mixture was poured into water $(100 \mathrm{~mL})$ and extracted with $\mathrm{CH}_{2} \mathrm{Cl}_{2}$. The organic layer was thoroughly washed with water and then dried over $\mathrm{Na}_{2} \mathrm{SO}_{4}$. After removal of solvent, the crude product was purified by column chromatography on silica gel using a mixture of hexane and dichloromethane (4:1, v:v) as eluant to afford Br-DPP $(0.75 \mathrm{~g}, 50 \%)$ as a deep red solid. ${ }^{1} \mathrm{H}$ NMR (400 MHz, CDCl3) $\delta 8.81(\mathrm{~s}, 1 \mathrm{H}), 8.54(\mathrm{~s}, 1 \mathrm{H}), 7.56(\mathrm{~s}, 1 \mathrm{H}), 7.19(\mathrm{~s}, 1 \mathrm{H})$, $7.14(\mathrm{~s}, 1 \mathrm{H}), 3.90(\mathrm{dd}, \mathrm{J}=30.2,7.8 \mathrm{~Hz}, 4 \mathrm{H}), 1.82(\mathrm{~s}, 2 \mathrm{H}), 1.18(\mathrm{~d}, \mathrm{~J}=29.5 \mathrm{~Hz}, 68 \mathrm{H}), 0.79$ (d, $\mathrm{J}=6.9 \mathrm{~Hz}, 12 \mathrm{H}) .{ }^{13} \mathrm{C} \mathrm{NMR}(101 \mathrm{MHz}, \mathrm{CDCl} 3) \delta 161.63,161.47,140.87,138.92,135.47$, $135.00,131.32,131.26,130.73,129.76,128.44,118.53,108.17,107.80,46.29,37.76,37.72$, $31.91,31.87,31.18,29.99,29.63,29.55,29.49,29.35,29.28,26.19,22.67,14.11$. HRMS $\left(\mathrm{MALDI}^{+}\right) \mathrm{m} / \mathrm{z}$ calcd. for $\left(\left[\mathrm{C}_{54} \mathrm{H}_{87} \mathrm{BrN}_{2} \mathrm{O}_{2} \mathrm{~S}_{2}\right]^{+}\right)$938.5392, found 938.6690.

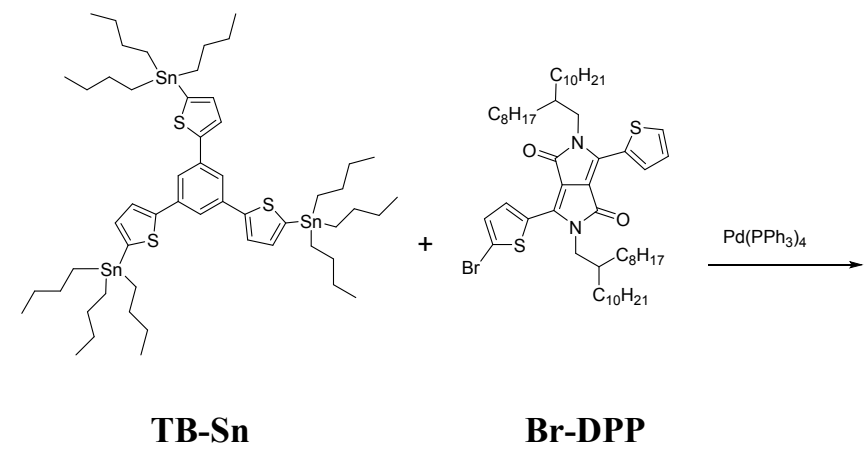

4) Synthesis of TB-DPP 
$\mathrm{Pd}\left(\mathrm{PPh}_{3}\right)_{4}(27 \mathrm{mg}, 0.023 \mathrm{mmol})$ was added to a solution of TB-Sn $(0.55 \mathrm{~g}, 0.47 \mathrm{mmol})$ and $\mathrm{Br}-$ DPP (1.58 g, $1.68 \mathrm{mmol})$ in toluene $(40 \mathrm{~mL})$ under $\mathrm{N}_{2}$. After being stirred at $110{ }^{\circ} \mathrm{C}$ for 24 hours, the reaction mixture was poured into water and extracted with dichloromethane. The organic layer was washed with water, and then dried over $\mathrm{Na}_{2} \mathrm{SO}_{4}$. After removal of solvent, the crude product was purified by column chromatography on silica gel using dichloromethane as eluant to afford TB-DPP $(1.10 \mathrm{~g}, 81 \%)$ as a purple solid. ${ }^{1} \mathrm{H}$ NMR $(400 \mathrm{MHz}, \mathrm{CDCl} 3) \delta 8.92$ $(\mathrm{d}, \mathrm{J}=4.1 \mathrm{~Hz}, 3 \mathrm{H}), 8.88(\mathrm{~d}, \mathrm{~J}=3.5 \mathrm{~Hz}, 3 \mathrm{H}), 7.42(\mathrm{~d}, \mathrm{~J}=3.7 \mathrm{~Hz}, 3 \mathrm{H}), 7.37$ (d, J = 4.1 Hz, 3H), $7.35(\mathrm{~d}, \mathrm{~J}=3.8 \mathrm{~Hz}, 3 \mathrm{H}), 4.05(\mathrm{~d}, \mathrm{~J}=5.2 \mathrm{~Hz}, 12 \mathrm{H}), 2.05-1.86(\mathrm{~m}, 6 \mathrm{H}), 1.39-1.14(\mathrm{~m}, 192 \mathrm{H})$, $0.90-0.80(\mathrm{~m}, 36 \mathrm{H}) .{ }^{13} \mathrm{C}$ NMR $(101 \mathrm{MHz}, \mathrm{CDCl} 3) \delta 161.24,143.23,142.16,139.63,139.33$, $136.55,136.34,135.25,134.83,130.17,129.84,128.29,128.22,128.16,125.69,124.62$, $107.96,107.92,107.83,107.80,65.23,53.38,46.19,41.92,38.92,38.69,37.81,37.67,35.37$, $34.07,31.90,31.88,31.87,31.29,31.19,30.08,29.68,29.63,29.59,29.52,29.45,29.36,29.32$, $29.08,28.99,27.91,26.37,26.23,23.29,23.06,22.92,22.67,22.62,20.11,19.11,14.37,14.11$, $14.10,11.36,11.06$

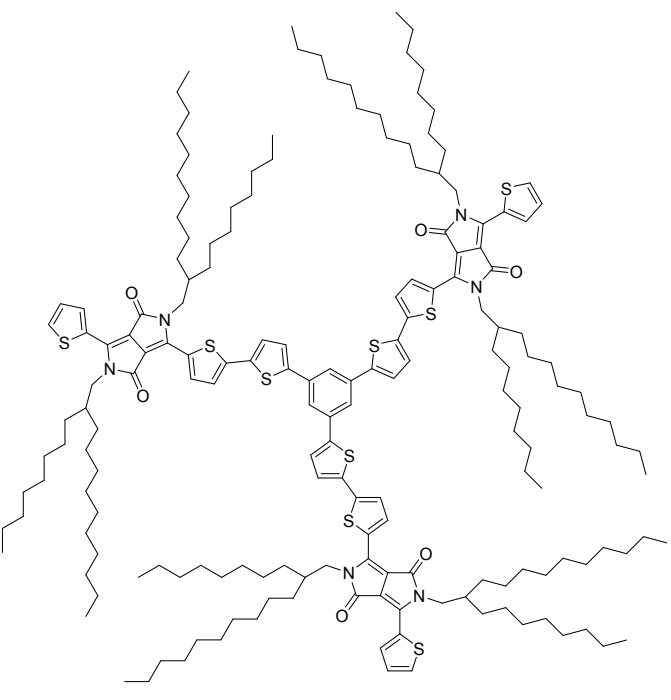

TB-DPP-Br

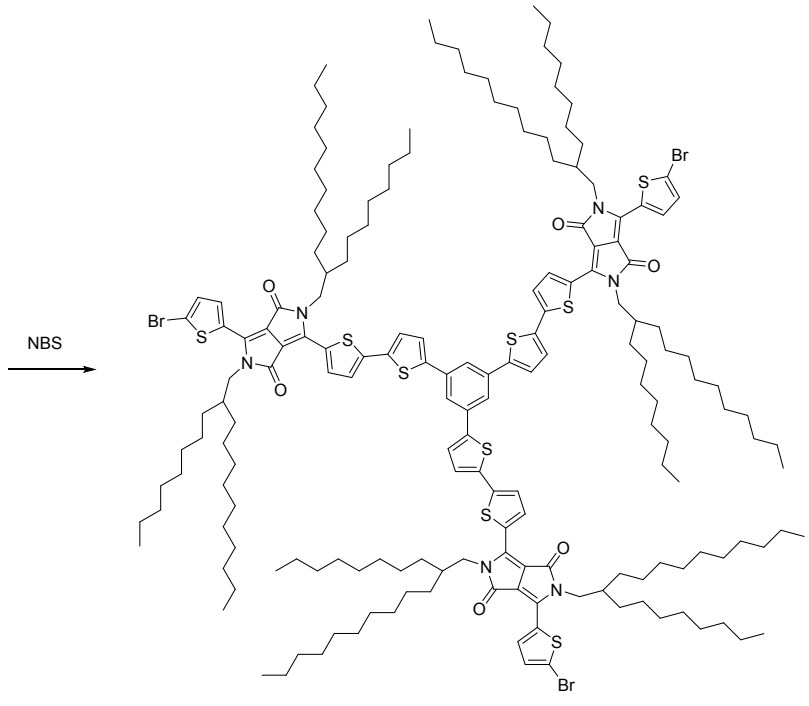

TB-DPP-Br

Scheme S3. Synthesis route of polymer monomer TB-DPP-Br. 


\section{5) Synthesis of TB-DPP-Br}

N-Bromosuccinimide (223 mg, $1.25 \mathrm{mmol}$ ) was added to a solution of compound TB-DPP $(1.10 \mathrm{~g}, 0.379 \mathrm{mmol})$ in anhydrous $\mathrm{CHCl}_{3}$ at $0{ }^{\circ} \mathrm{C}$. After being stirred for $12 \mathrm{~h}$ at room temperature in dark, the reaction mixture was poured into water $(100 \mathrm{~mL})$ and extracted with $\mathrm{CH}_{2} \mathrm{Cl}_{2}$. The organic layer was thoroughly washed with water and then dried over $\mathrm{Na}_{2} \mathrm{SO}_{4}$. After removal of solvent, the crude product was purified by column chromatography on silica gel using dichloromethane as eluant to afford TB-DPP-Br $(0.98 \mathrm{~g}, 82 \%)$ as a deep purple solid. 1H NMR (400 MHz, CDCl3) $\delta 8.65$ (s, 3H), 8.40 (s, 3H), 7.49 (d, J = 4.0 Hz, 3H), 7.29 (s, 3H), $7.24-7.19(\mathrm{~m}, 3 \mathrm{H}), 7.10(\mathrm{~d}, \mathrm{~J}=3.5 \mathrm{~Hz}, 3 \mathrm{H}), 7.00(\mathrm{~d}, \mathrm{~J}=3.1 \mathrm{~Hz}, 3 \mathrm{H}), 3.95(\mathrm{~s}, 12 \mathrm{H}), 1.83(\mathrm{~s}$, 6H), $1.32-1.18(\mathrm{~m}, 192 \mathrm{H}), 0.89-0.82(\mathrm{~m}, 36 \mathrm{H}) .13 \mathrm{C}$ NMR (101 MHz, CDCl3) $\delta 160.99$, $160.78,143.38,142.70,139.55,138.12,136.54,134.97,134.66,131.20,130.94,128.20$, $125.64,124.48,124.41,124.38,120.54,118.70,107.77,107.56,46.15,37.50,31.93,31.91$, $31.89,31.31,30.07,29.71,29.65,29.61,29.58,29.54,29.38,29.36,29.34,26.37,26.31,22.68$, 14.12. HRMS (MALDI $\left.{ }^{+}\right) \mathrm{m} / \mathrm{z}$ calcd. for $\left(\left[\mathrm{C}_{180} \mathrm{H}_{267} \mathrm{Br}_{3} \mathrm{~N}_{6} \mathrm{O}_{6} \mathrm{~S}_{9}\right]^{+}\right) 3133.5809$, found 3133.1933 .

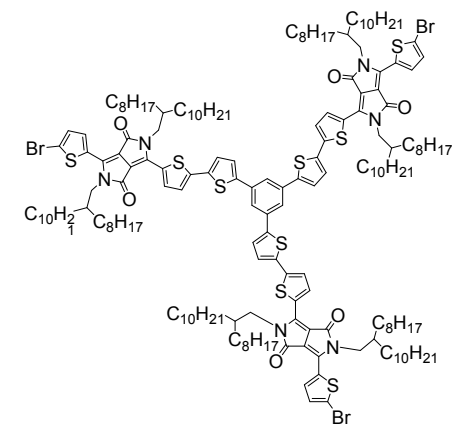

TB-DPP-Br

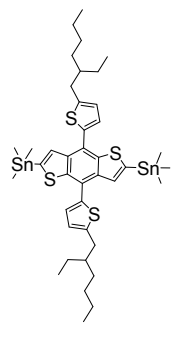

BDTT-Sn

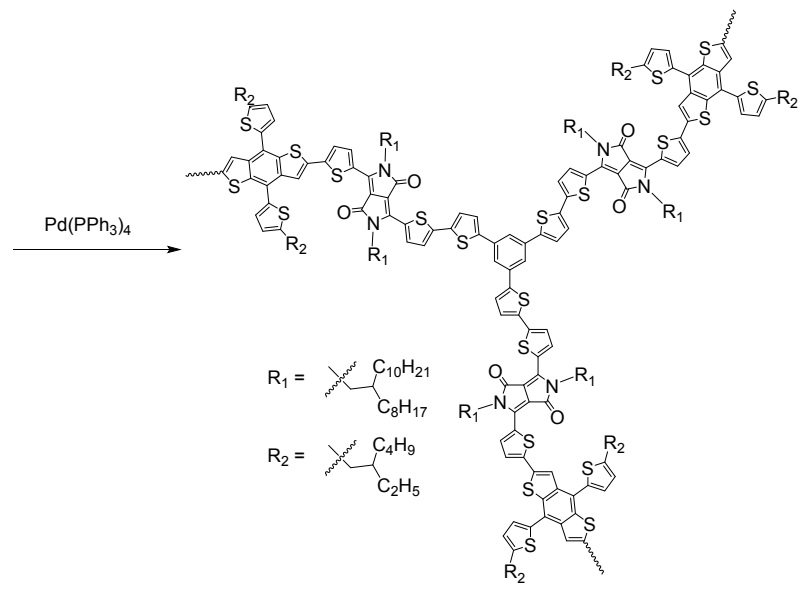

2DP-TDB

Scheme S4. Synthesis routes of 2DP-TDB. 
6) Synthesis of 2DP-TDB.

Under nitrogen atmosphere, BDTT-Sn (34.6 mg, $0.0382 \mathrm{mmol})$, TB-DPP-Br (80 mg, 0.0255 mmol), and $\mathrm{Pd}\left(\mathrm{PPh}_{3}\right)_{4}(6.8 \mathrm{mg}, 0.0019 \mathrm{mmol})$ were mixed and dissolved in degassed toluene $(8 \mathrm{~mL})$ and DMF $(0.5 \mathrm{~mL})$. The reaction was stirred at room temperature for $5 \mathrm{~min}$ and then heated to $110{ }^{\circ} \mathrm{C}$ at $400 \mathrm{rpm}$ for $5.5 \mathrm{~h}$. After cooling to room temperature, the mixture was precipitated into methanol $(100 \mathrm{ml})$. The crude polymer was then collected by filtration and purified by column chromatography on silica gel using chloroform as eluant to afford 2DPTDB as a black solid. $(69 \mathrm{mg}, 72 \%) . \mathrm{GPC}\left(\mathrm{THF}, 40^{\circ} \mathrm{C}\right): \mathrm{Mn}=119 \mathrm{~K}, \mathrm{Mw}=251 \mathrm{~K}, \mathrm{PDI}=2.10$. 
4. Supporting Figures

Broad Unknown Relative Chromatogram

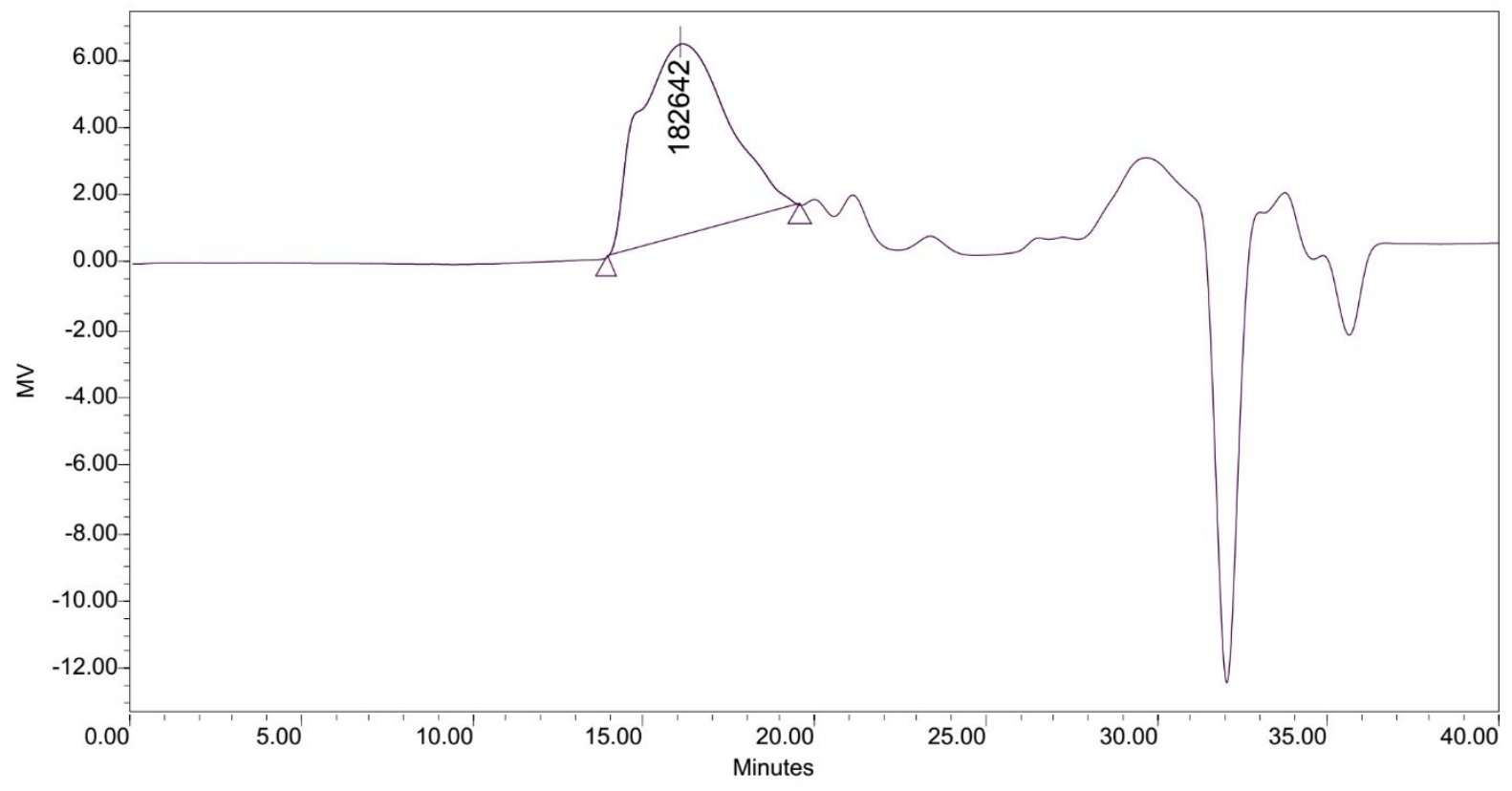

Broad Unknown Relative Peak Table

\begin{tabular}{|l|l|r|r|r|r|r|r|r|r|}
\hline & $\begin{array}{c}\text { Distribution } \\
\text { Name }\end{array}$ & $\begin{array}{c}\text { Mn } \\
\text { (Daltons) }\end{array}$ & $\begin{array}{c}\text { Mw } \\
\text { (Daltons ) }\end{array}$ & $\begin{array}{c}\text { MP } \\
\text { (Daltons ) }\end{array}$ & $\begin{array}{c}\text { Mz } \\
\text { (Daltons ) }\end{array}$ & $\begin{array}{c}\text { Mz+1 } \\
\text { (Daltons ) }\end{array}$ & Polydispersity & Mz/Mw & Mz+1/Mw \\
\hline 1 & & 119390 & 250734 & 182642 & 465977 & 652884 & 2.100129 & 1.858447 & 2.603890 \\
\hline
\end{tabular}

Figure S1. GPC data of the first batch of 2DP-TDB. GPC was measured using THF as the mobile phase. The polymerization time was 5.5 hours. 


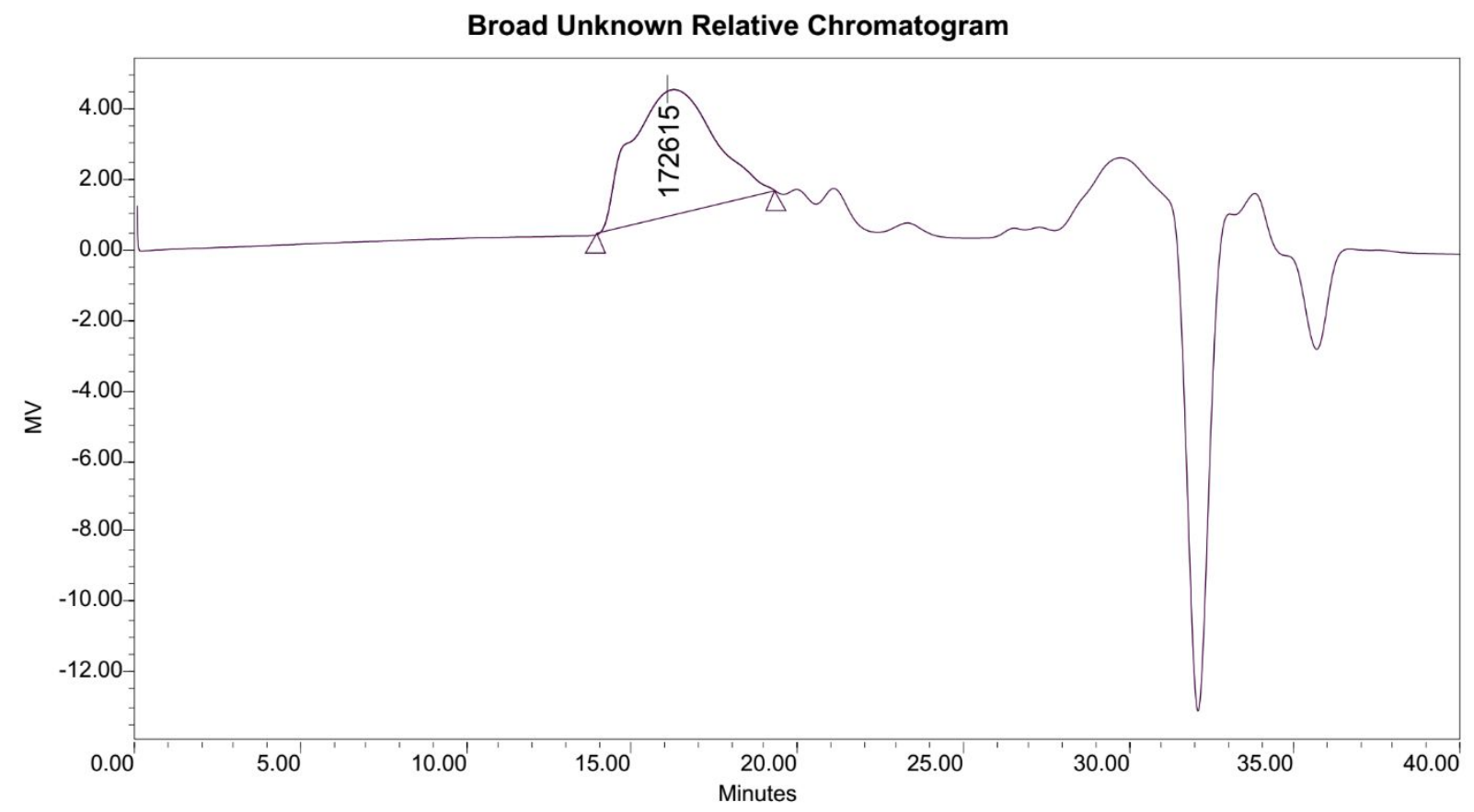

\begin{tabular}{|c|c|c|c|c|c|c|c|c|c|}
\hline \multicolumn{10}{|c|}{ Broad Unknown Relative Peak Table } \\
\hline & $\begin{array}{l}\text { Distribution } \\
\text { Name }\end{array}$ & \begin{tabular}{|c|}
$\mathrm{Mn}$ \\
(Daltons )
\end{tabular} & $\begin{array}{c}\mathrm{Mw} \\
\text { (Daltons) }\end{array}$ & $\begin{array}{c}\text { MP } \\
\text { (Daltons ) }\end{array}$ & $\begin{array}{c}\mathrm{Mz} \\
\text { (Daltons ) }\end{array}$ & $\begin{array}{c}\mathrm{Mz}+1 \\
\text { (Daltons) }\end{array}$ & Polydispersity & $\mathrm{Mz} / \mathrm{Mw}$ & $\mathrm{Mz}+1 / \mathrm{Mw}$ \\
\hline 1 & & 119502 & 243090 & 172615 & 452363 & 641319 & 2.034187 & 1.860891 & 2.638200 \\
\hline
\end{tabular}

Figure S2. GPC data of the second batch of 2DP-TDB. GPC was measured using THF as the mobile phase. The polymerization time was 5.5 hours. 


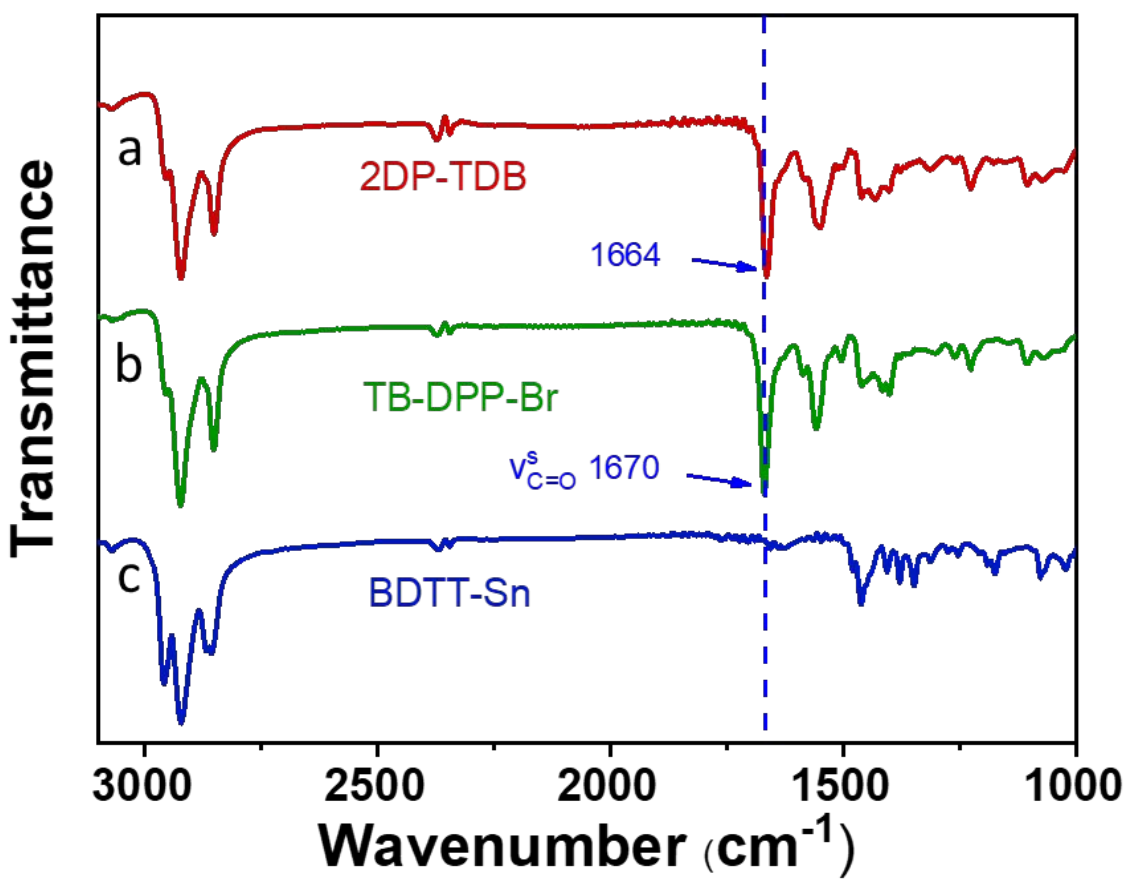

Figure S3. FT-IR spectra of a) 2DP-TDB, b) TB-DPP-Br, c) BDTT-Sn 


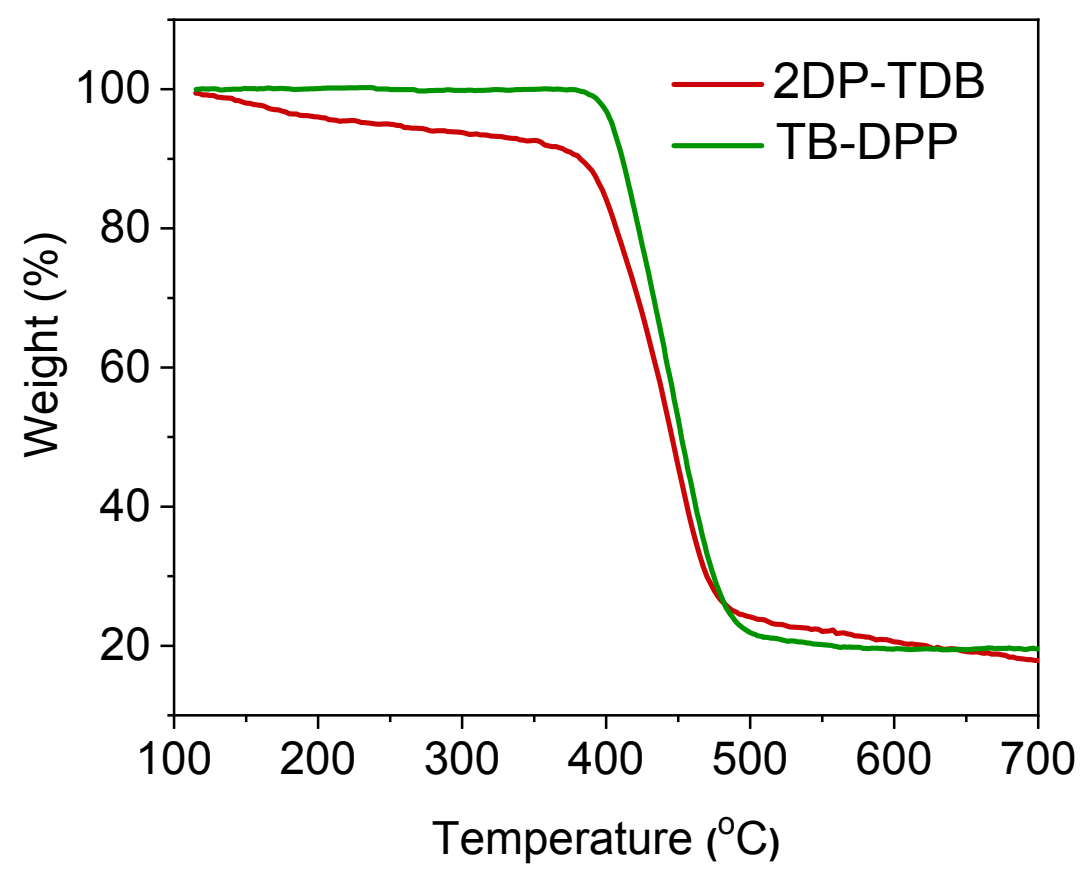

Figure S4. Thermal analysis. TGA curve of 2DP-TDB and TB-DPP. The two material was stable until $390{ }^{\circ} \mathrm{C}$. 


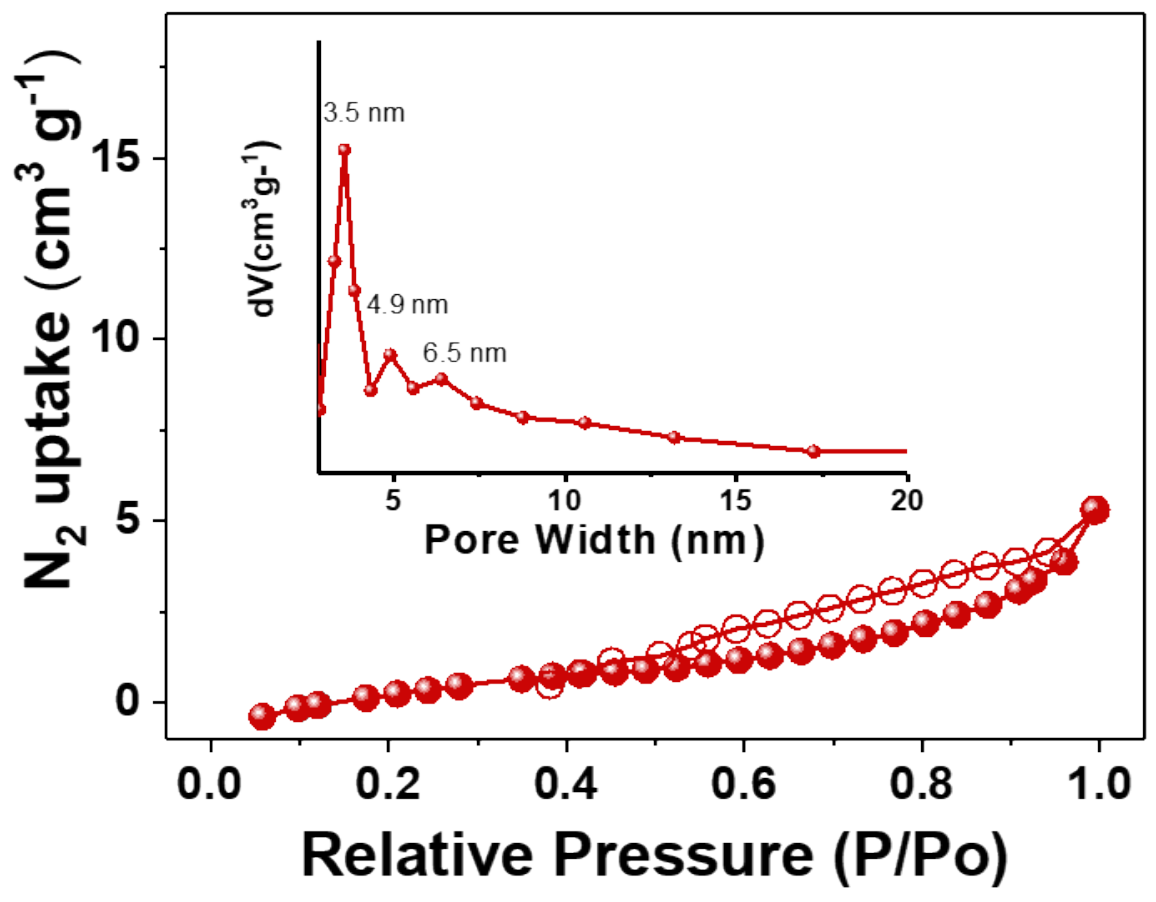

Figure S5. Nitrogen adsorption-desorption isotherms of 2DP-TDB with inset showing pore size distribution profiles. 


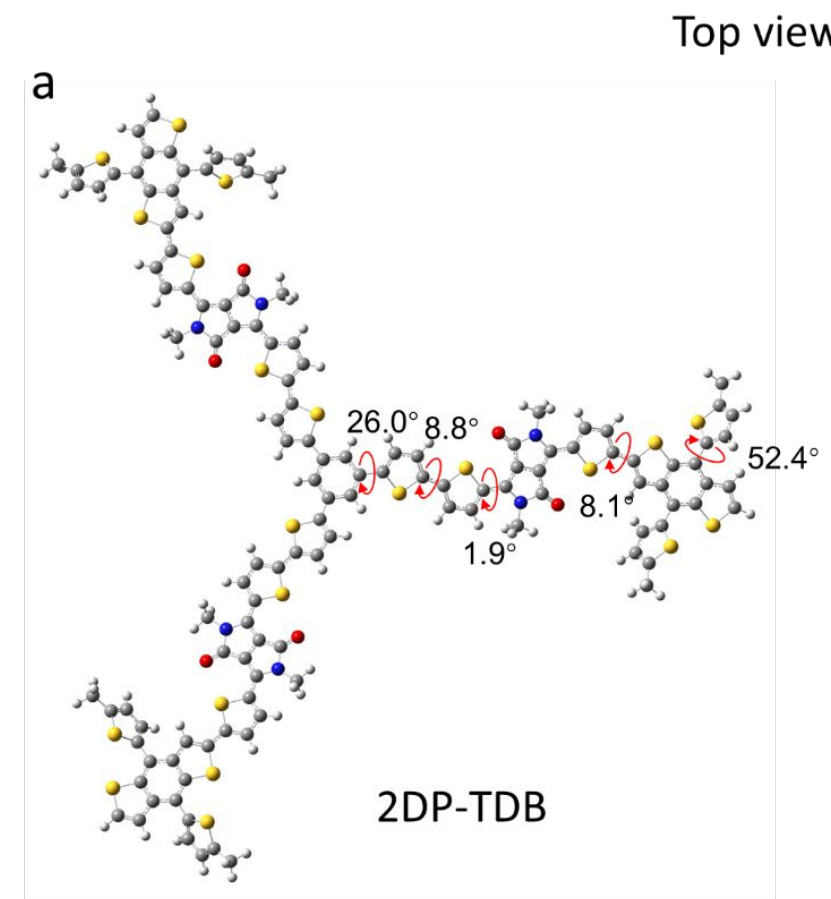

b
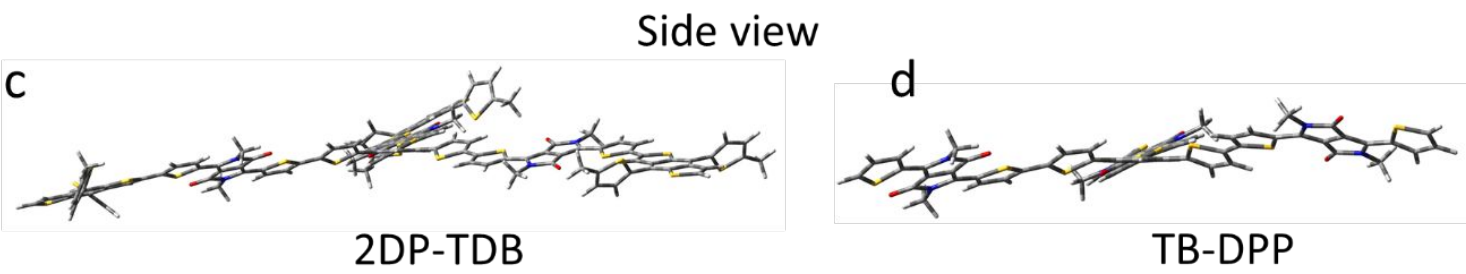

Figure S6. Top view of optimized (a) 2DP-TDB and (b) TB-DPP geometries obtained by density functional theory (DFT) calculations. Side view of optimized (c) 2DP-TDB and (d) TBDPP geometries obtained by density functional theory (DFT) calculations. The large aliphatic groups were substituted with methyl groups to accelerate the computations. 

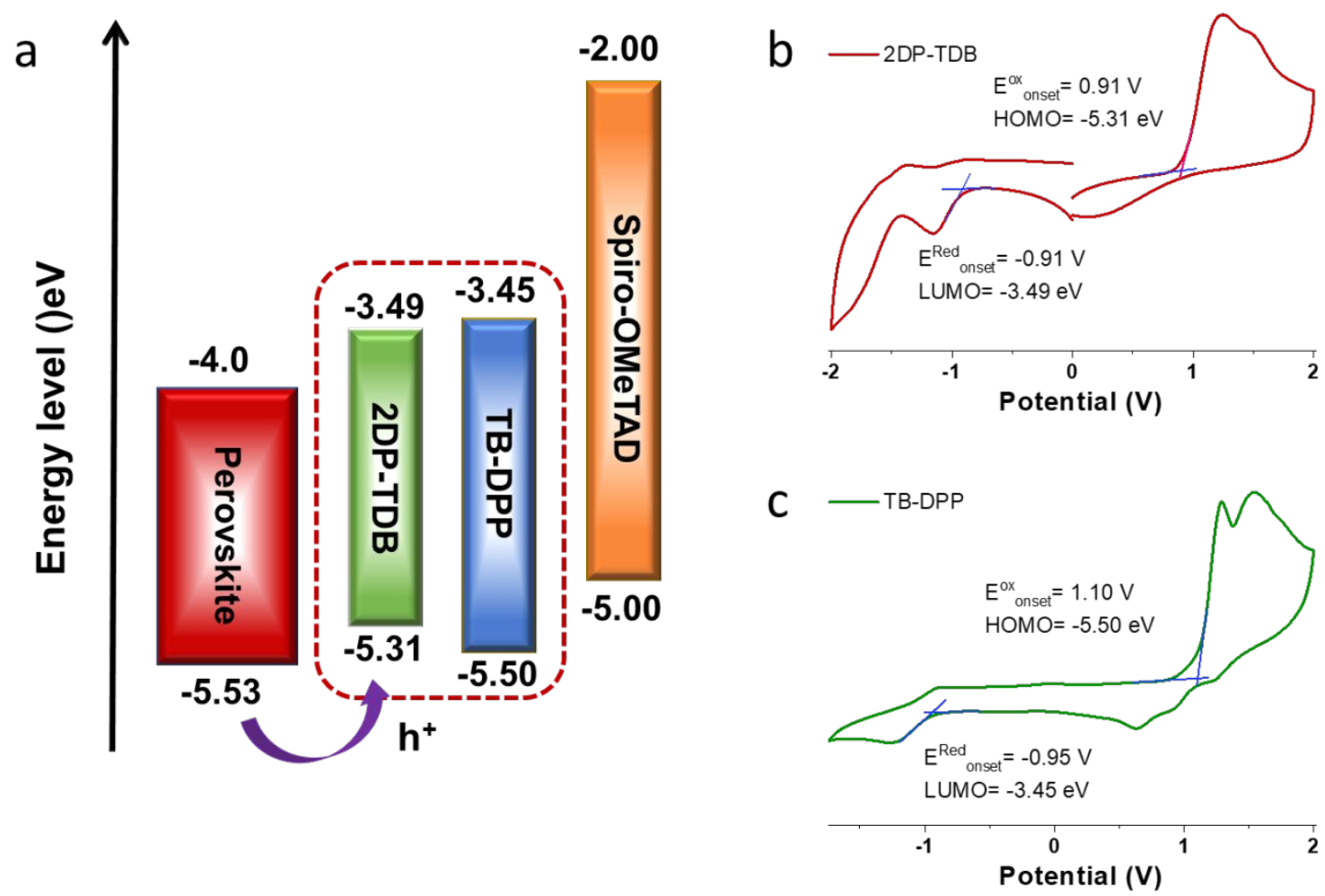

Figure S7. (a) Schematic diagram of energy level arrangement. (b,c) Cyclic voltammogram of 2DP-TDB film (b) and TB-DPP film (c) measured at room temperature in a $0.1 \mathrm{~mol} \mathrm{~L}^{-1}$ $\mathrm{Bu}_{4} \mathrm{NPF}_{6}$ acetonitrile solution, and the scan rate was $100 \mathrm{mV} \mathrm{s}^{-1}$. 


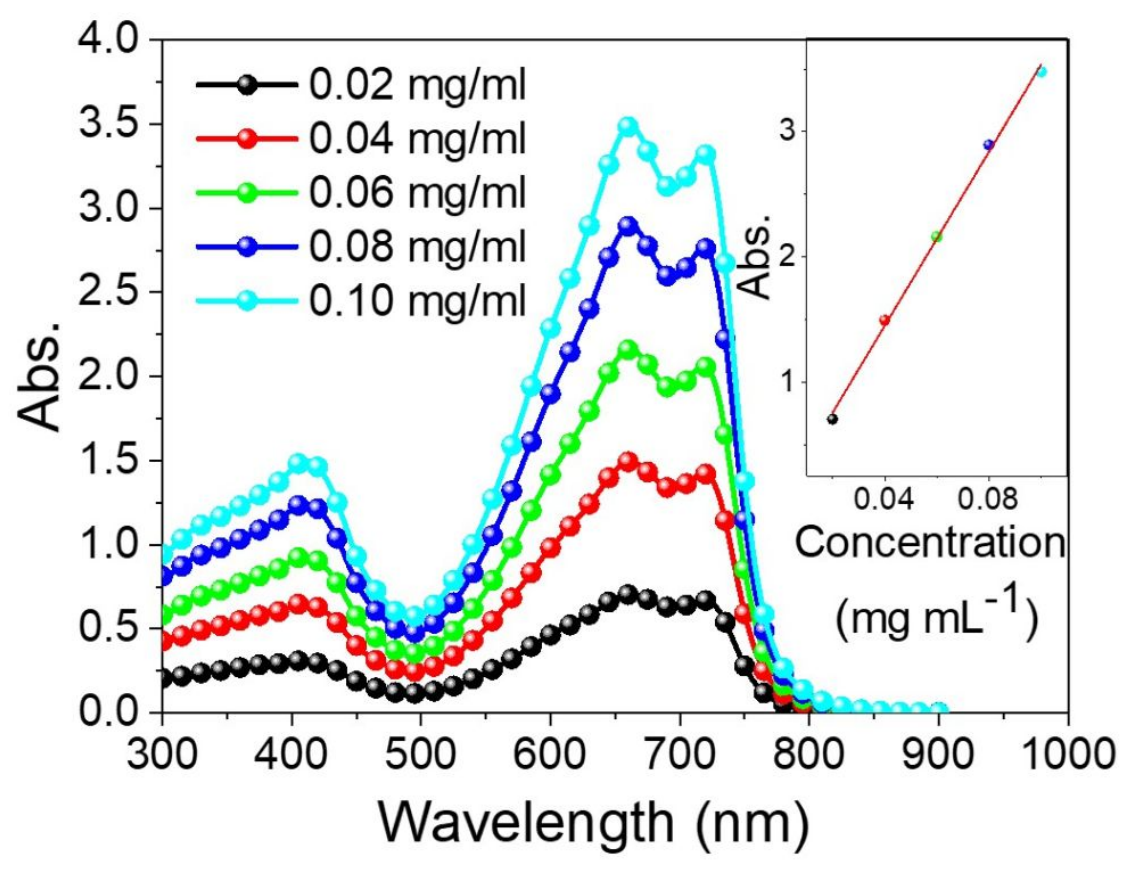

Figure S8. UV-vis absorption spectra of 2DP-TDB in chloroform with different concentrations from 0.02 to $0.10 \mathrm{mg} \mathrm{mL}^{-1}$. Inset is the linear fitting of absorption intensity at the absorption maximum $(662 \mathrm{~nm})$ for the corresponding 2DP-TDB solutions. 


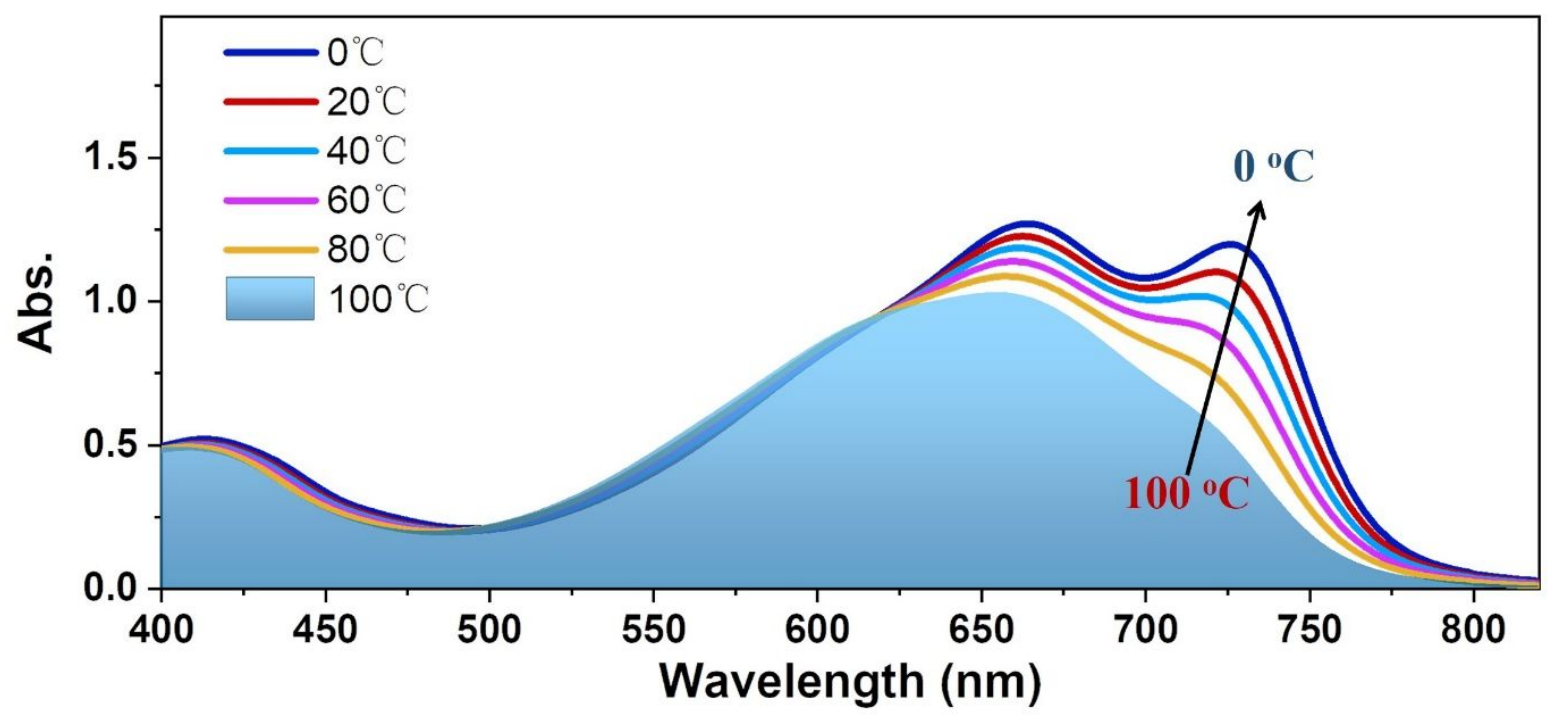

Figure S9. Temperature-dependent UV-vis spectroscopy. UV-vis spectra of 2DP-TDB in DCB under different temperatures. 

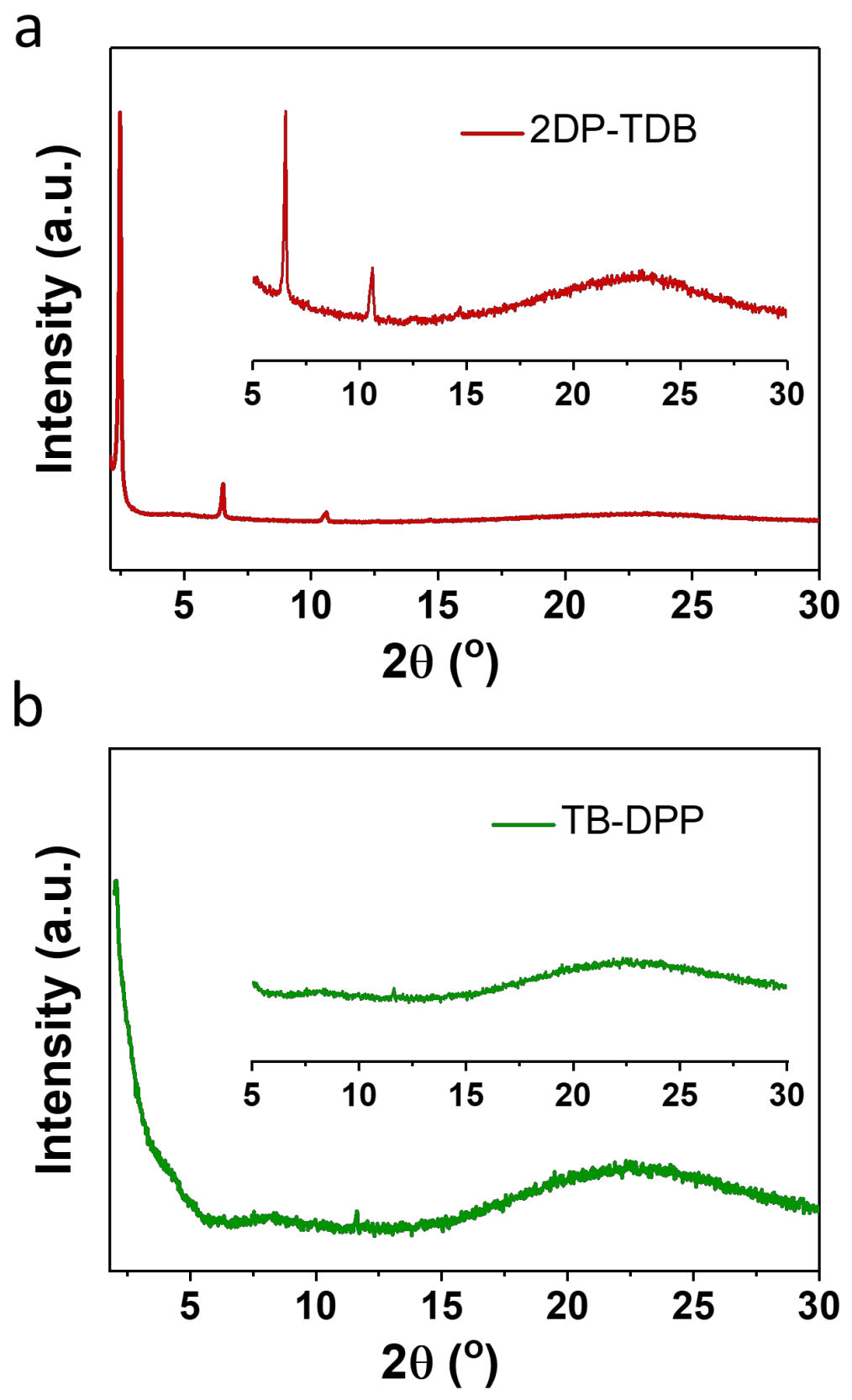

Figure S10. (a,b) Experimental XRD patterns of 2DP-TDB film (a) and TB-DPP film (b). 

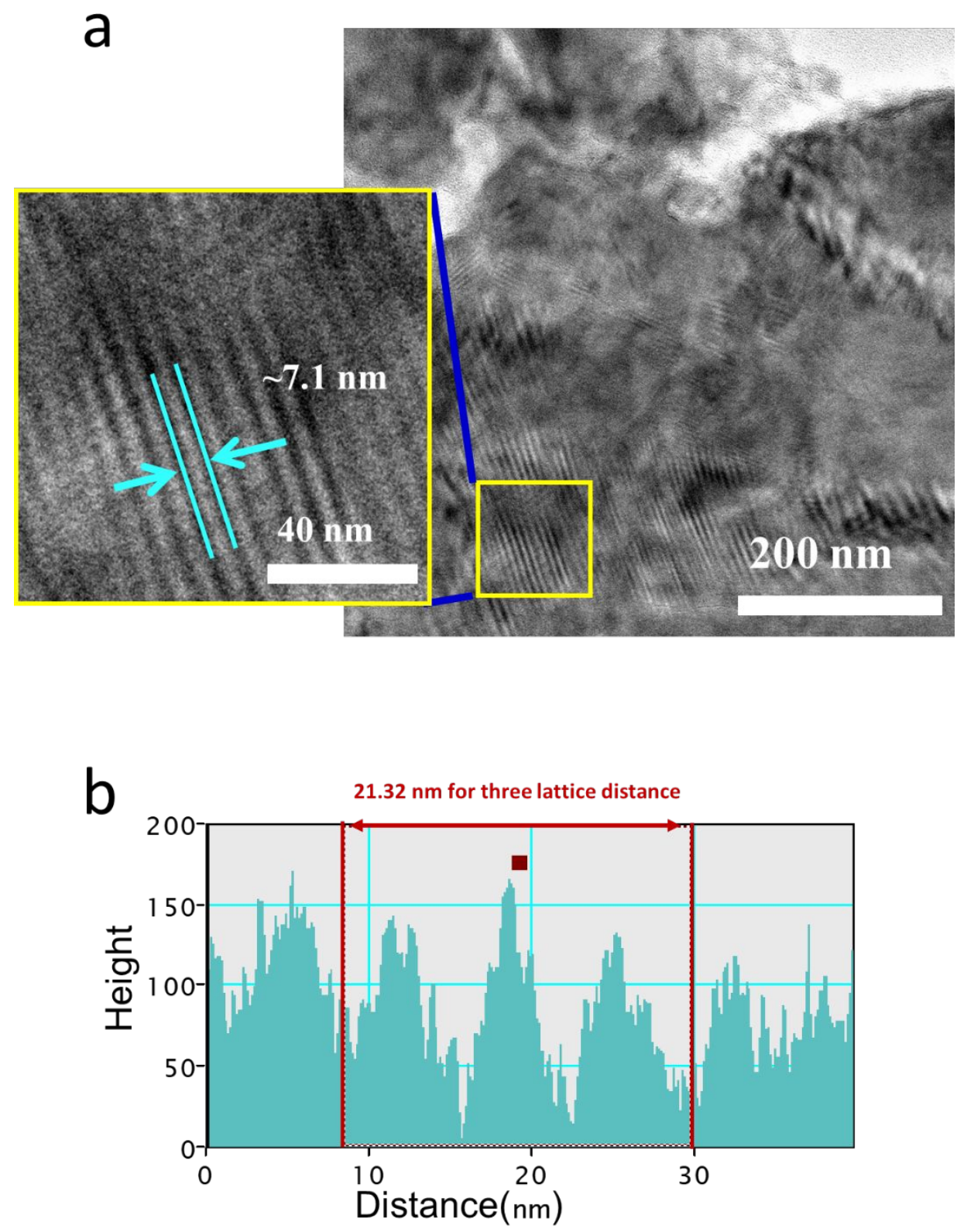

Figure S11. (a) HR-TEM images of 2DP-TDB films from toluene suspensions showing the crystalline in about $100 \mathrm{~nm}$ domain. (b) Lattice fringe distance measurement of the red line showing the average lattice distance of $7.1 \mathrm{~nm}$. 

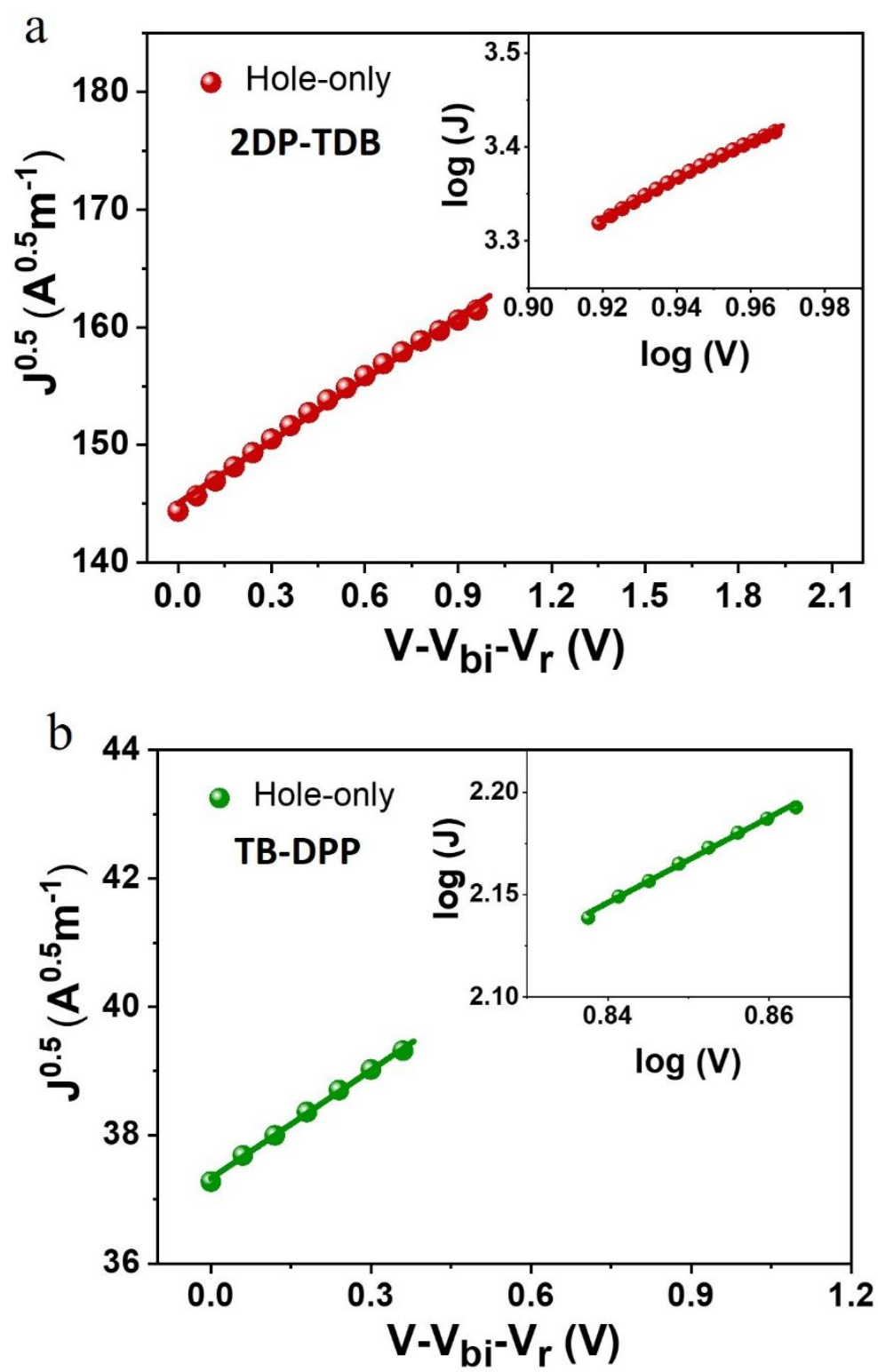

Figure S12. SCLC mobility data. $J-V$ curves of the hole-only devices for (a) 2DP-TDB and (b) TB-DPP films in the SCLC region. The insets are the $\log (\mathrm{J})-\log (\mathrm{V})$ plots of the devices in the SCLC region with a slop of 2.0. The solid lines are fits of the data points. The hole mobility of 2DP-TDB film is $2.08 \times 10^{-4} \mathrm{~cm}^{2} \mathrm{~V}^{-1} \mathrm{~s}^{-1}$. The hole mobility of TB-DPP film is $1.32 \times 10^{-6} \mathrm{~cm}^{2} \mathrm{~V}^{-1}$ $\mathrm{s}^{-1}$ 


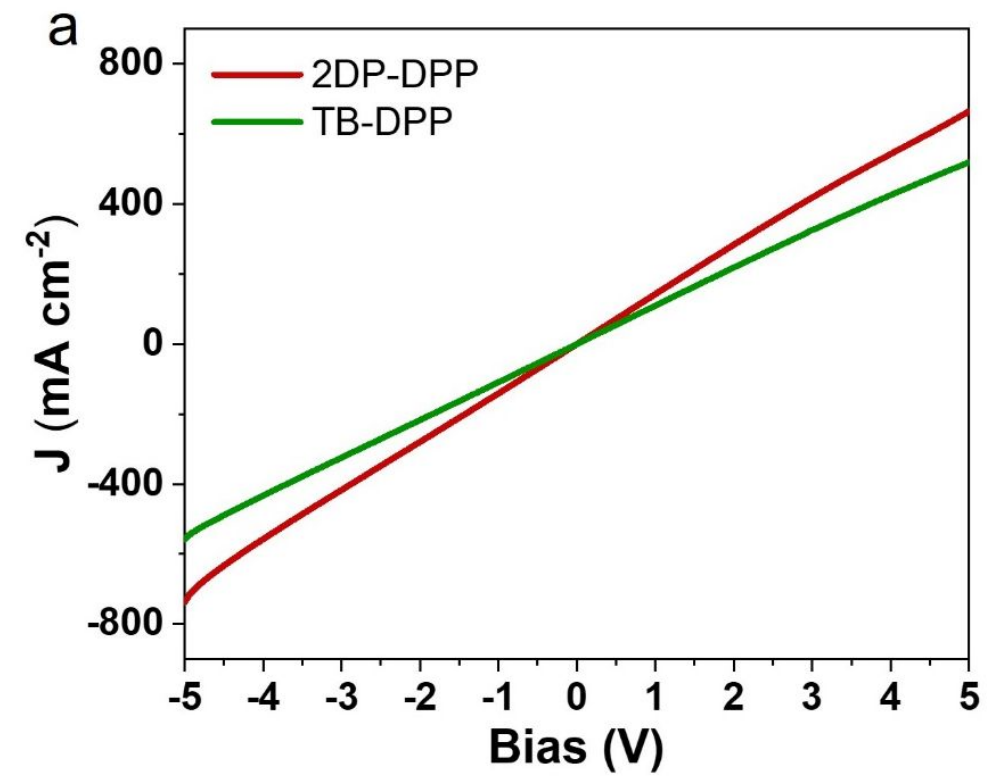

b

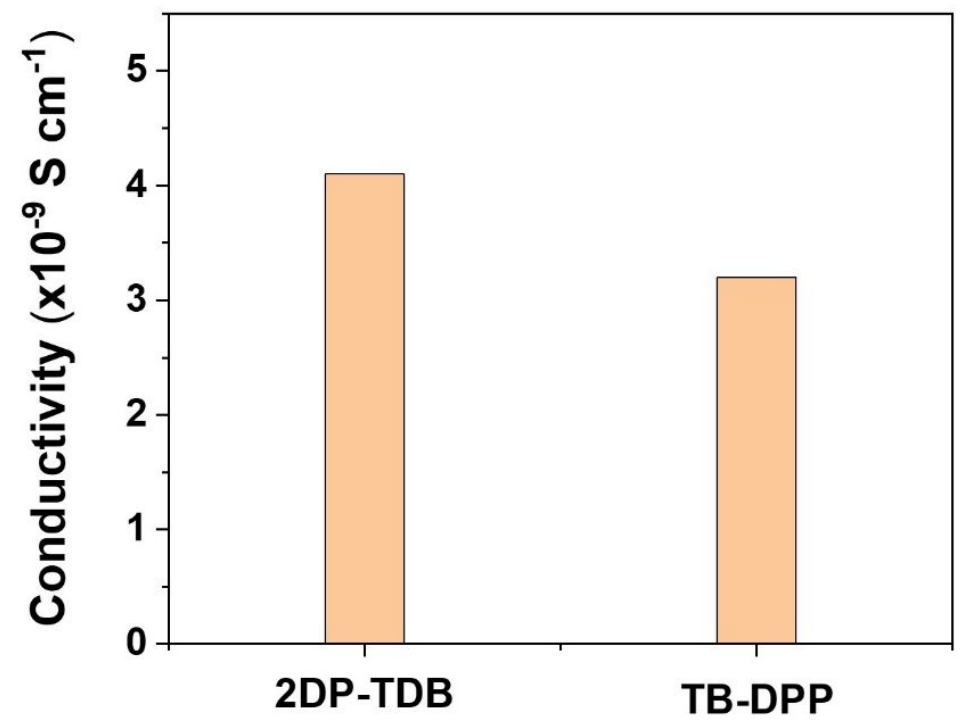

Figure S13. Conductivity data. (a) Linear $J-V$ characteristics and (b) derived conductivity plot of the dopant-free HTMs films. 


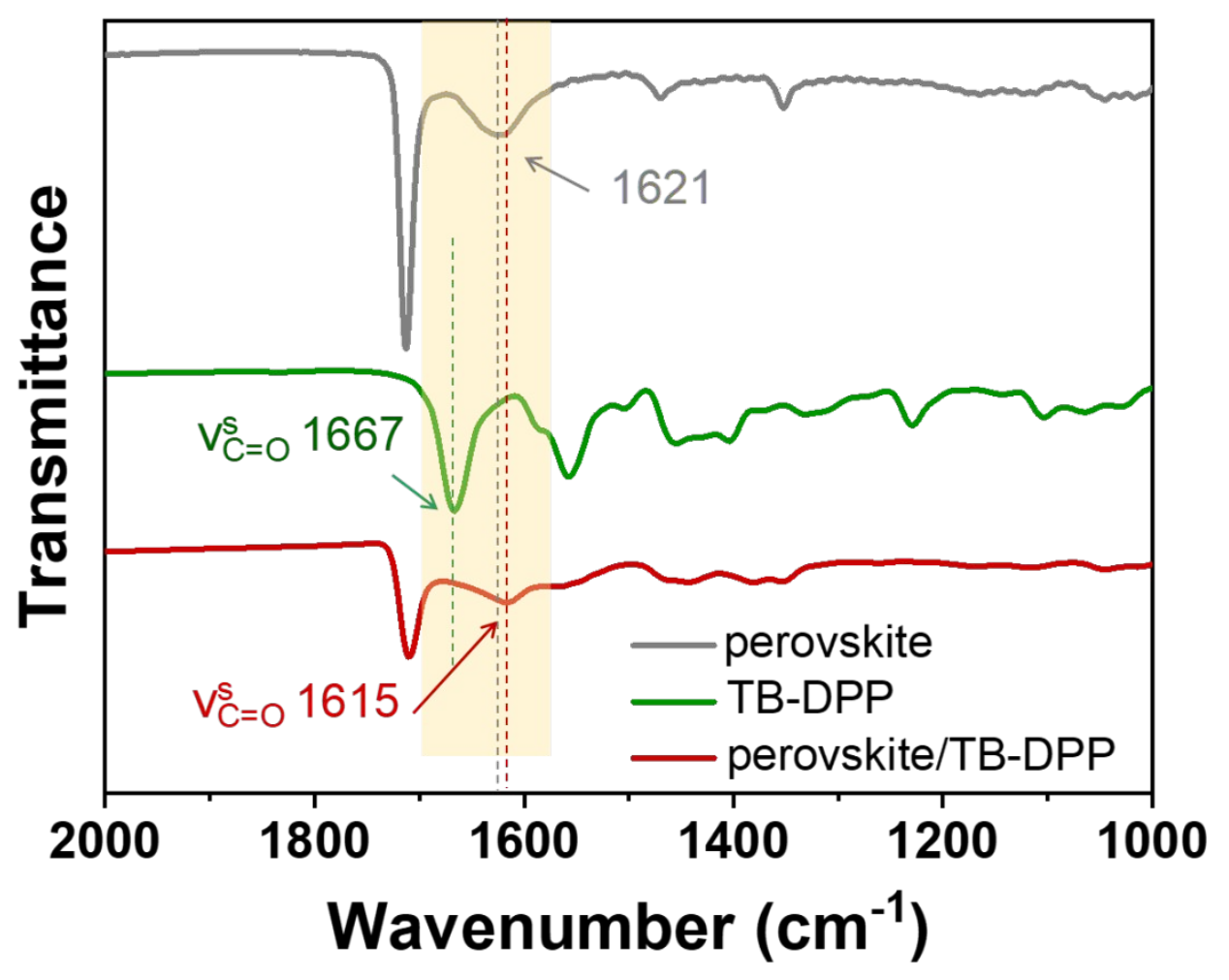

Figure S14. FTIR spectra of the pristine perovskite film, pristine TB-DPP film, and perovskite film coated with TB-DPP. 

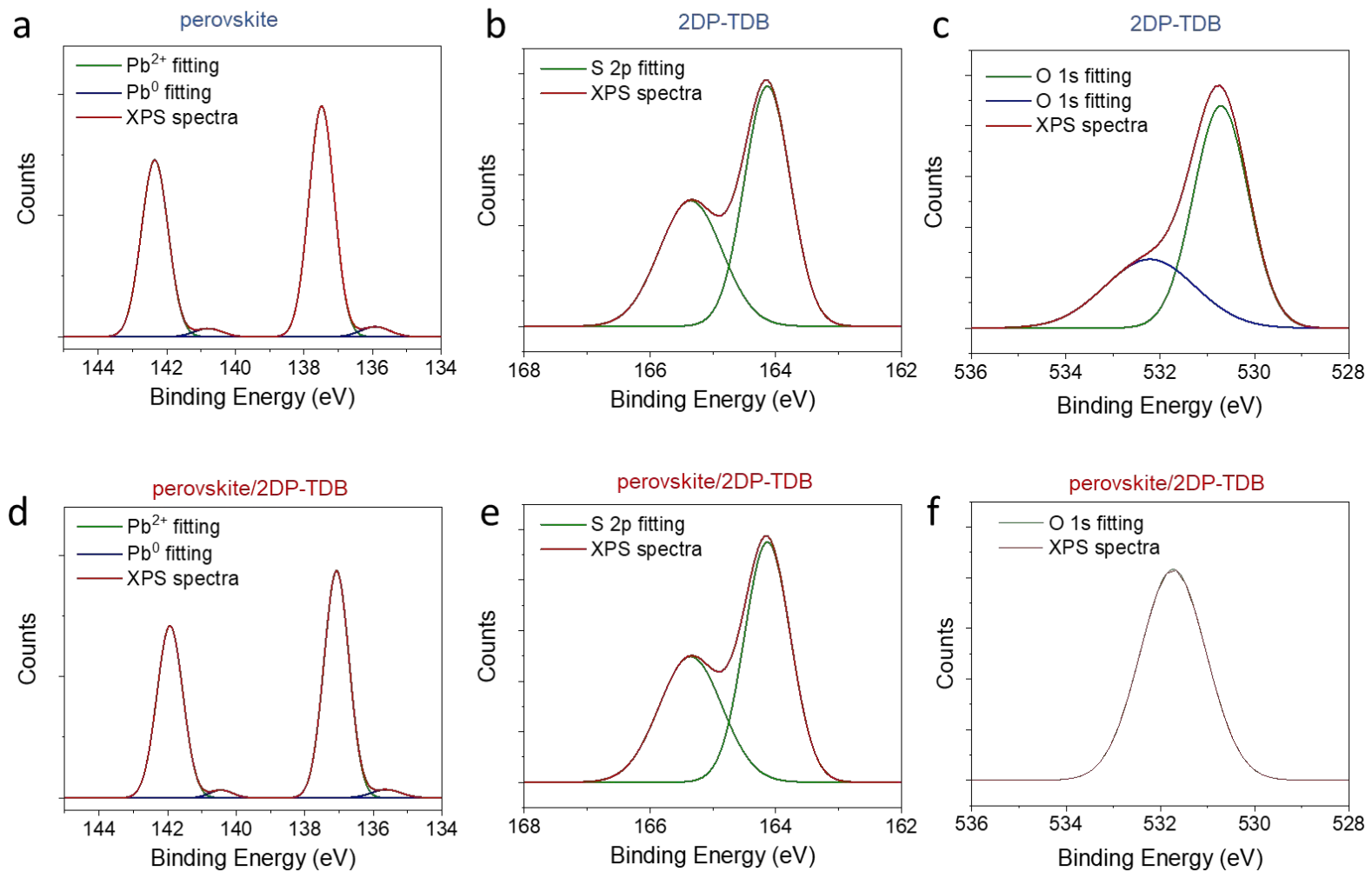

Figure S15. (a,d) XPS of Pb 4f peaks of the pristine perovskite film and 2DP-TDB coated perovskite film. (b,e) XPS of S $2 p$ peaks of the pristine 2DP-TDB film, and perovskite film coated with 2DP-TDB. (c,f) XPS of O 1s peaks of the pristine 2DP-TDB film, and perovskite film coated with 2DP-TDB. O 1s shoulder peak of 2DP-TDB can be attributed to water in 2DPTDB. 
a

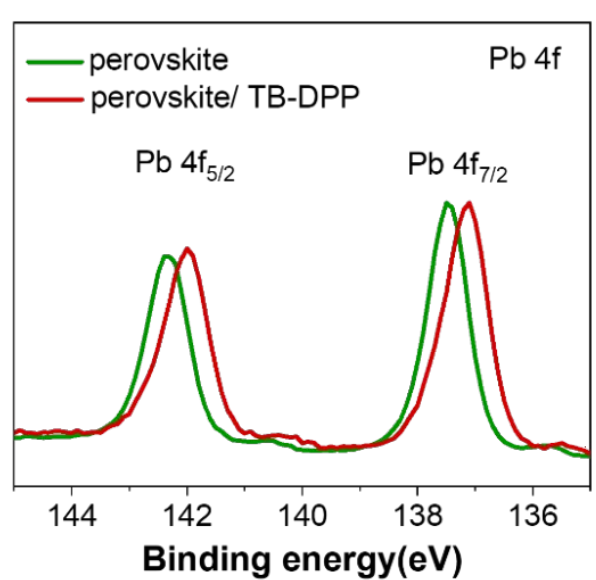

b

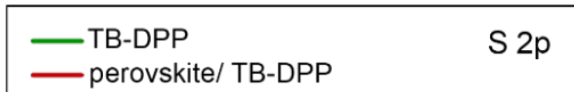

$S 2 p_{3 / 2}$

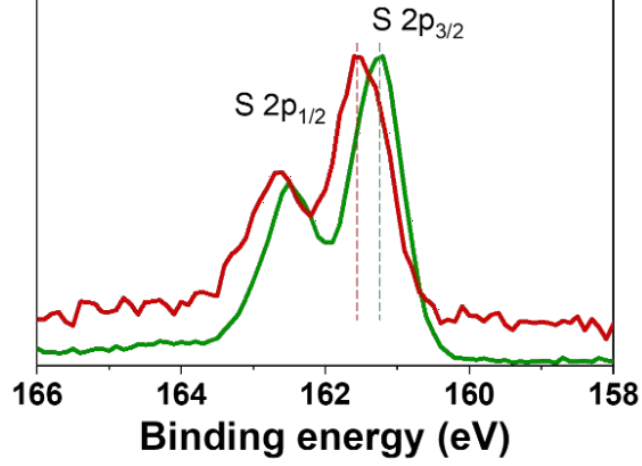

C

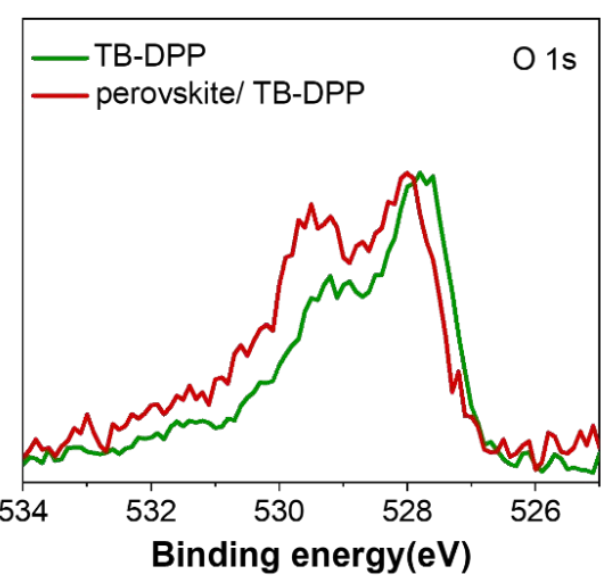

Figure S16. (a) XPS of $\mathrm{Pb} 4 \mathrm{f}$ peaks of the pristine perovskite film and TB-DPP coated perovskite film. (b) XPS of S 2p peaks of the pristine TB-DPP film, and perovskite film coated with TB-DPP. (c) XPS of O 1s peaks of the pristine TB-DPP film, and perovskite film coated with TB-DPP. 

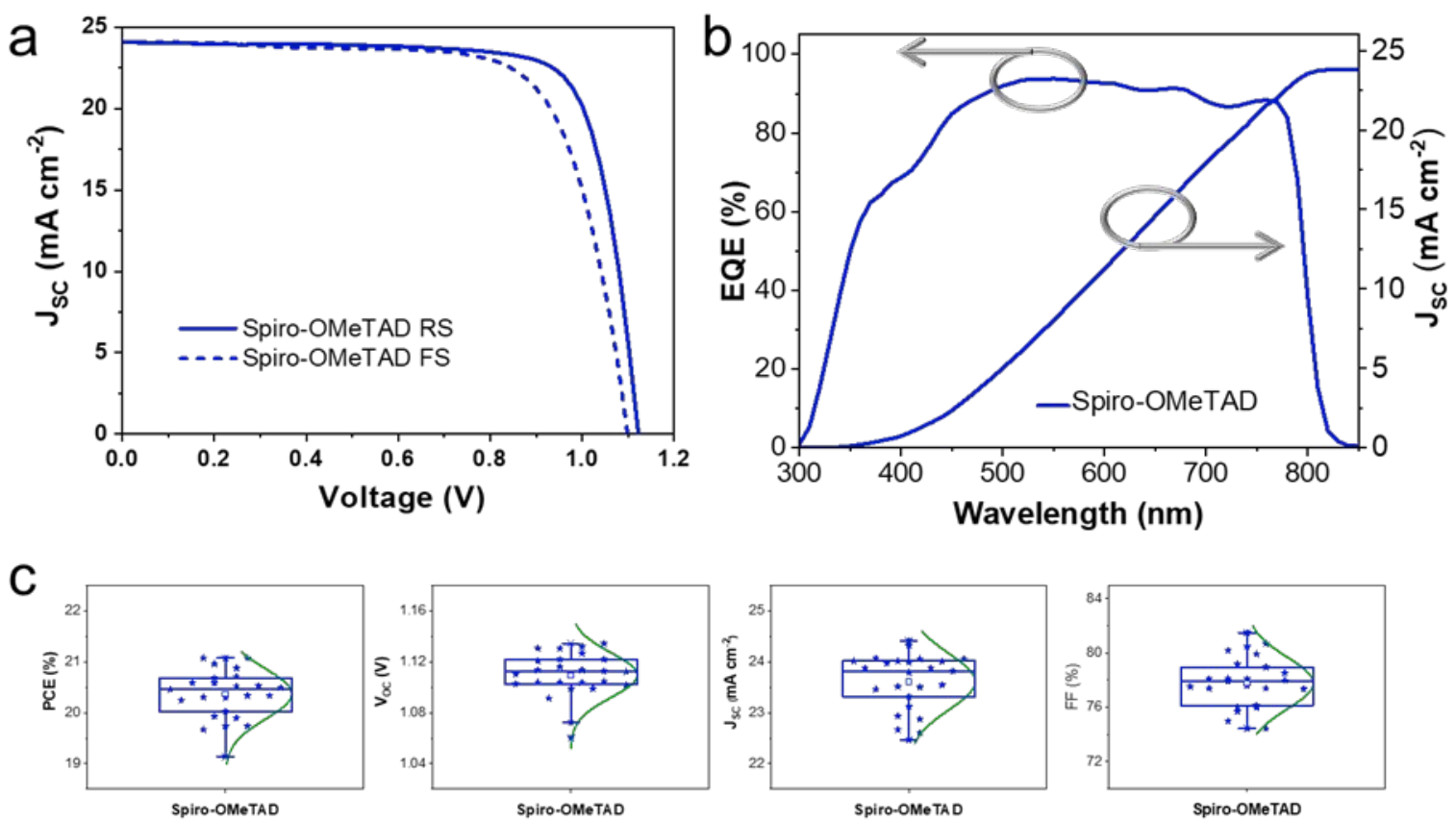

Figure S17. (a) $J-V$ curves of the Spiro-OMeTAD based device under AM1.5G, $100 \mathrm{~mW} \mathrm{~cm}-$

2 illumination. (b) EQE spectra of the corresponding photovoltaic devices. (c) Photovoltaic performance variations for 25 individual solar cells based on Spiro-OMeTAD. 


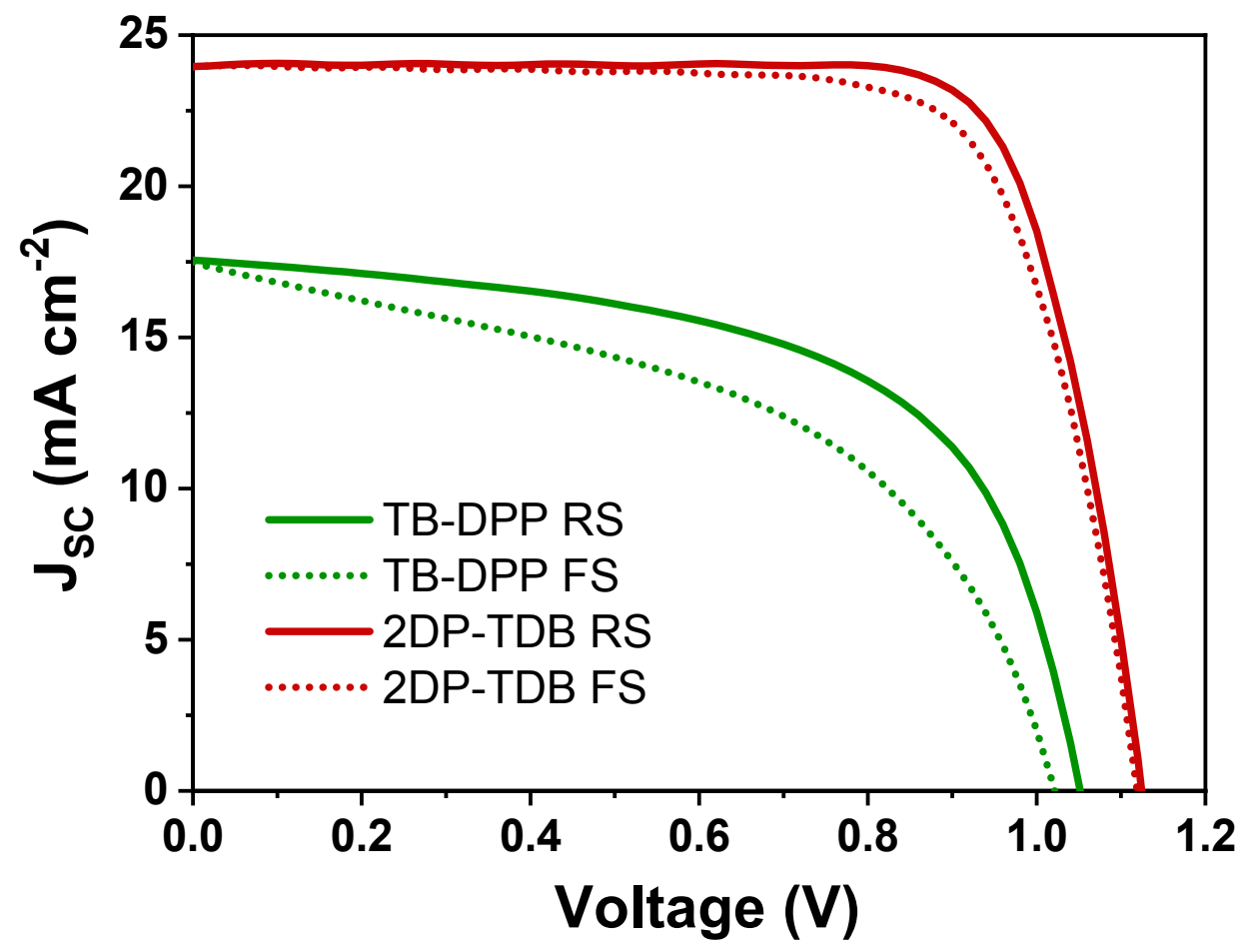

Figure S18. Photovoltaic performance and $J-V$ measurements with a reverse scan (RS) $(1.2 \mathrm{~V}$ $\rightarrow 0.2 \mathrm{~V}$, step $0.02 \mathrm{~V})$ and forward scan $(\mathrm{RS})(-0.2 \mathrm{~V} \rightarrow 1.2 \mathrm{~V}$, step $0.02 \mathrm{~V})$, respectively. 


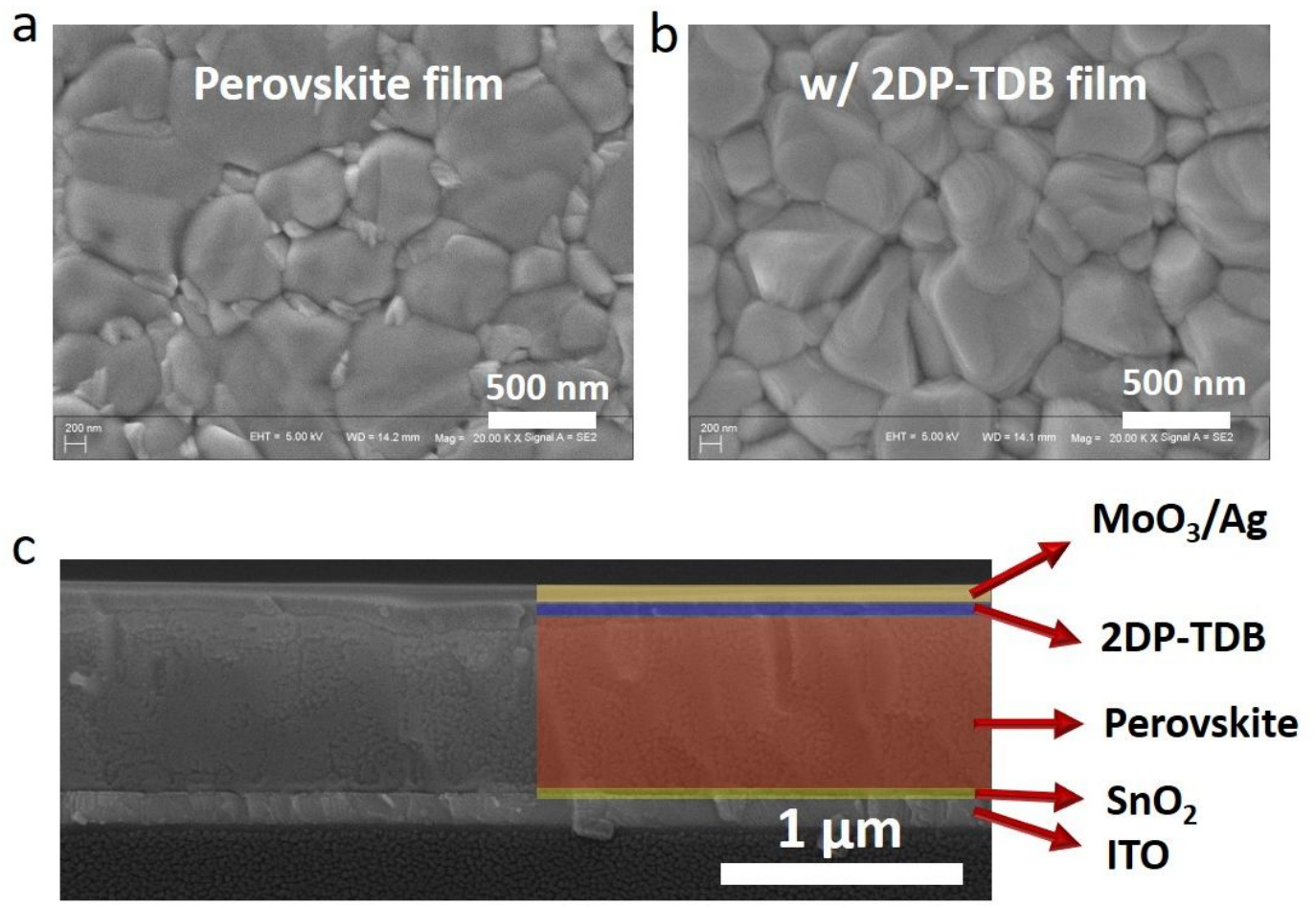

Figure S19. SEM images. (a,b) Top SEM image of pristine perovskite film and perovskite film capped with 2DP-TDB HTM. (c) Cross-sectional SEM images of the $n-i-p$ perovskite solar cells structure with 2DP-TDB HTM. 

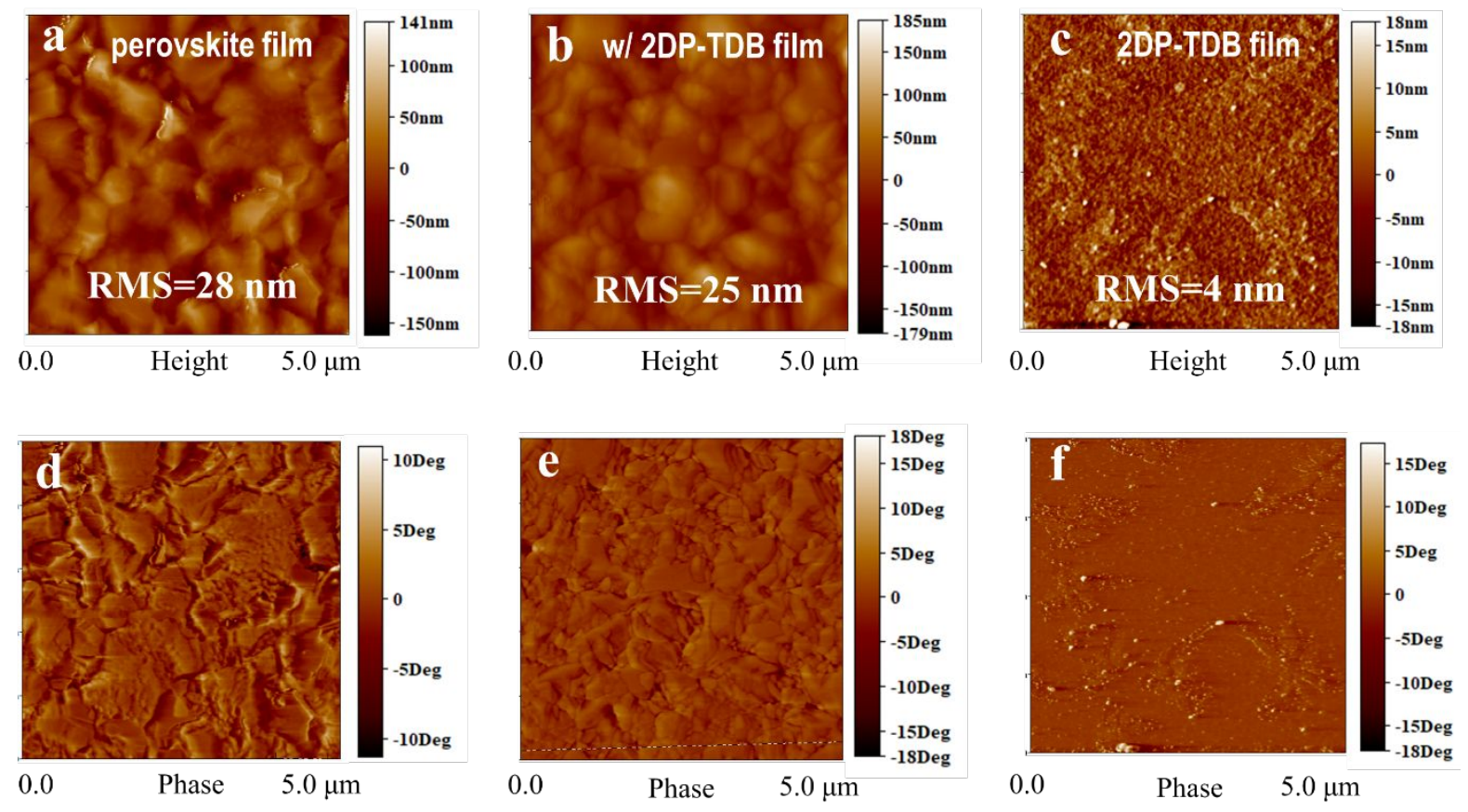

Figure S20. Tapping-mode AFM height and phase images $(5 \times 5 \mu \mathrm{m})$ of $(\mathrm{a}, \mathrm{d})$ perovskite film, (b, e) perovskite capped with 2DP-TDB film and (c, f) bare 2DP-TDB film. 


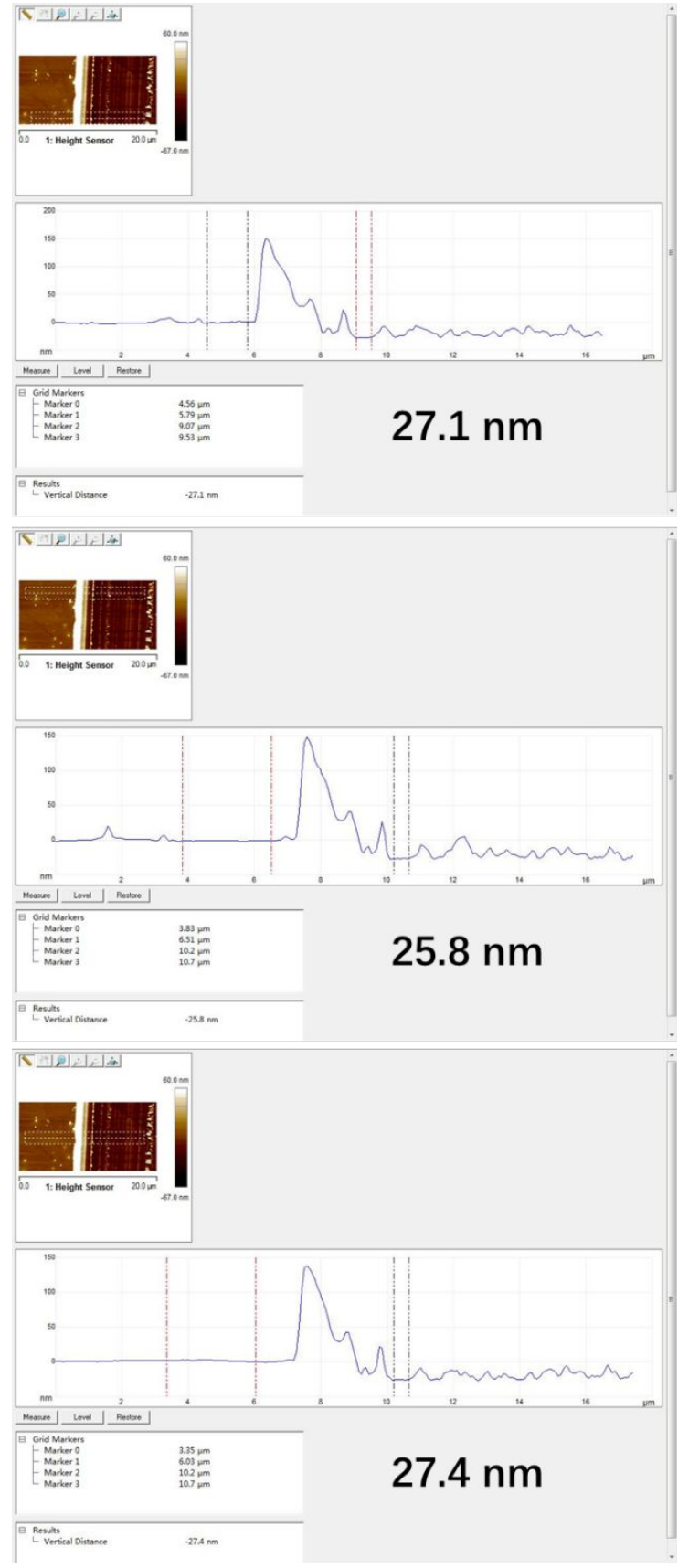

Figure S21. Tapping-mode AFM height images $(5 \times 5 \mu \mathrm{m})$ showing that the thickness of 2DPTDB HTL is about $27 \mathrm{~nm}$. 


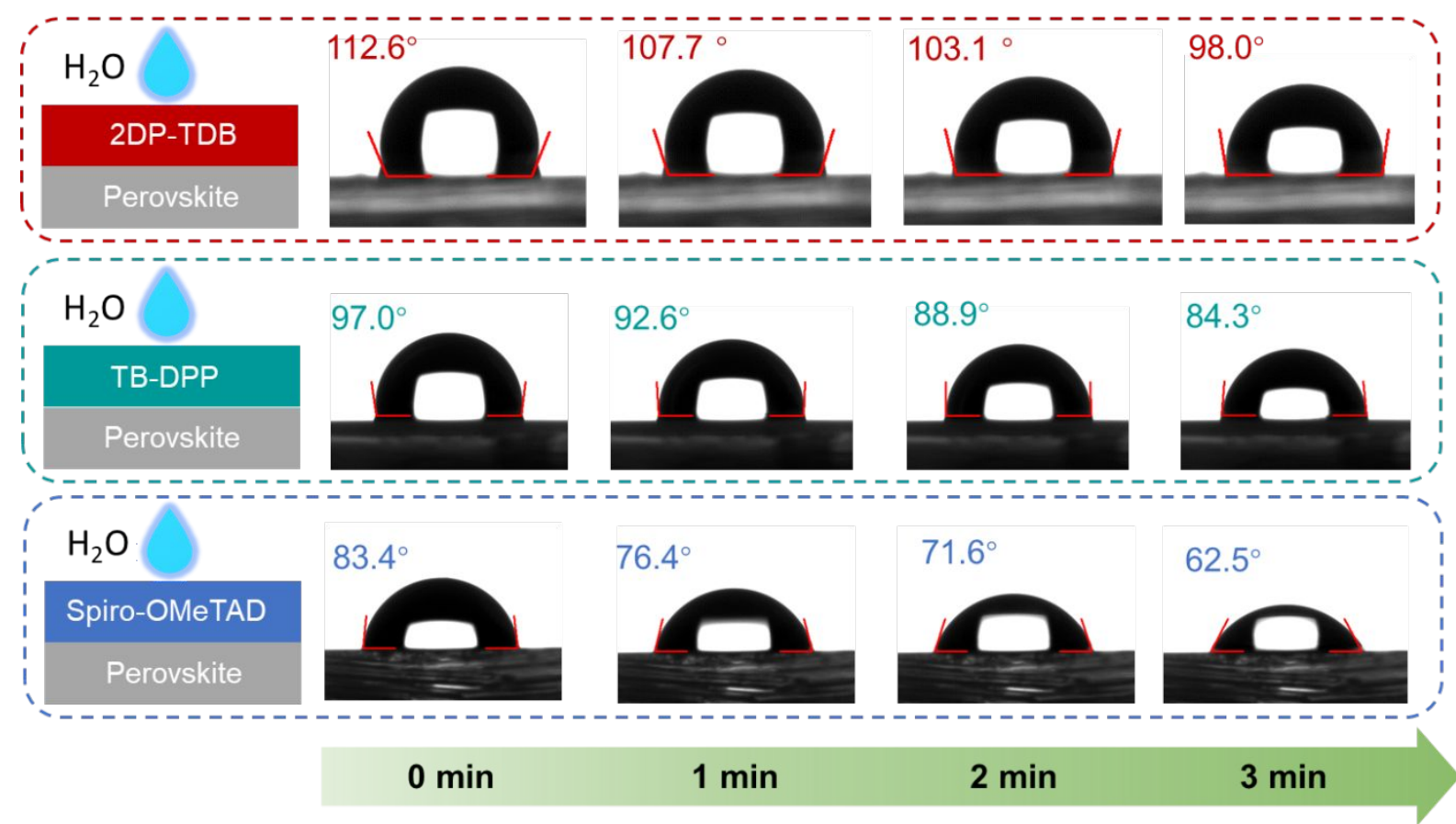

Figure S22. Images of water droplet contact angles on surfaces of 2DP-TDB, TB-DPP and spiro-OMeTAD with glass/ITO/ $\mathrm{SnO}_{2} /$ perovskite as substrates at different loading times. 


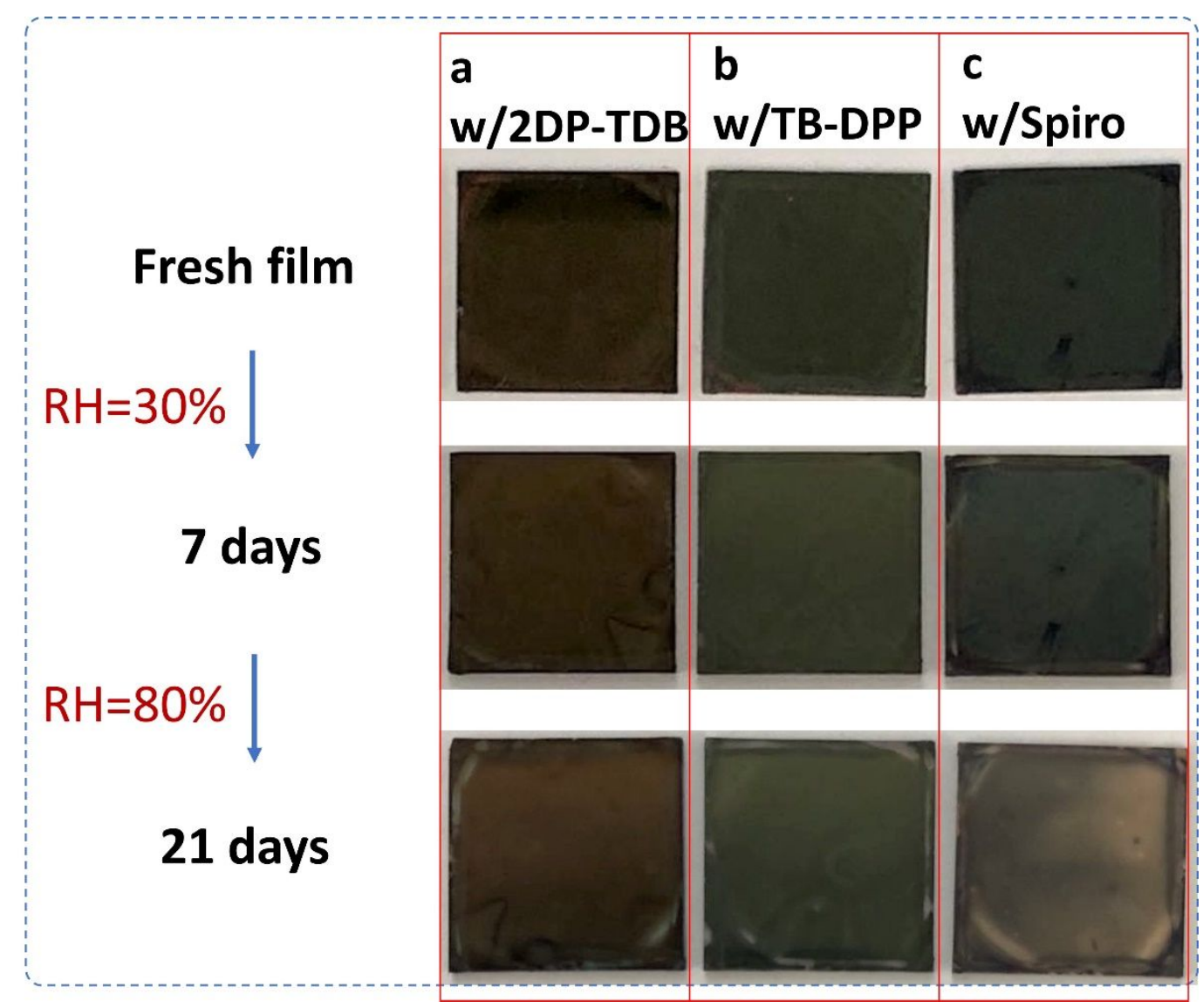

Figure S23. Degradation evolution of perovskite films covered with (a) 2DP-TDB, (b) TP-DPP and (c) Spiro-OMeTAD HTMs under ambient conditions with a temperature of $25{ }^{\circ} \mathrm{C}$ and relative humidity of $\sim 30 \%$ for 7 days and relative humidity of $\sim 80 \%$ for subsequent 14 days. 

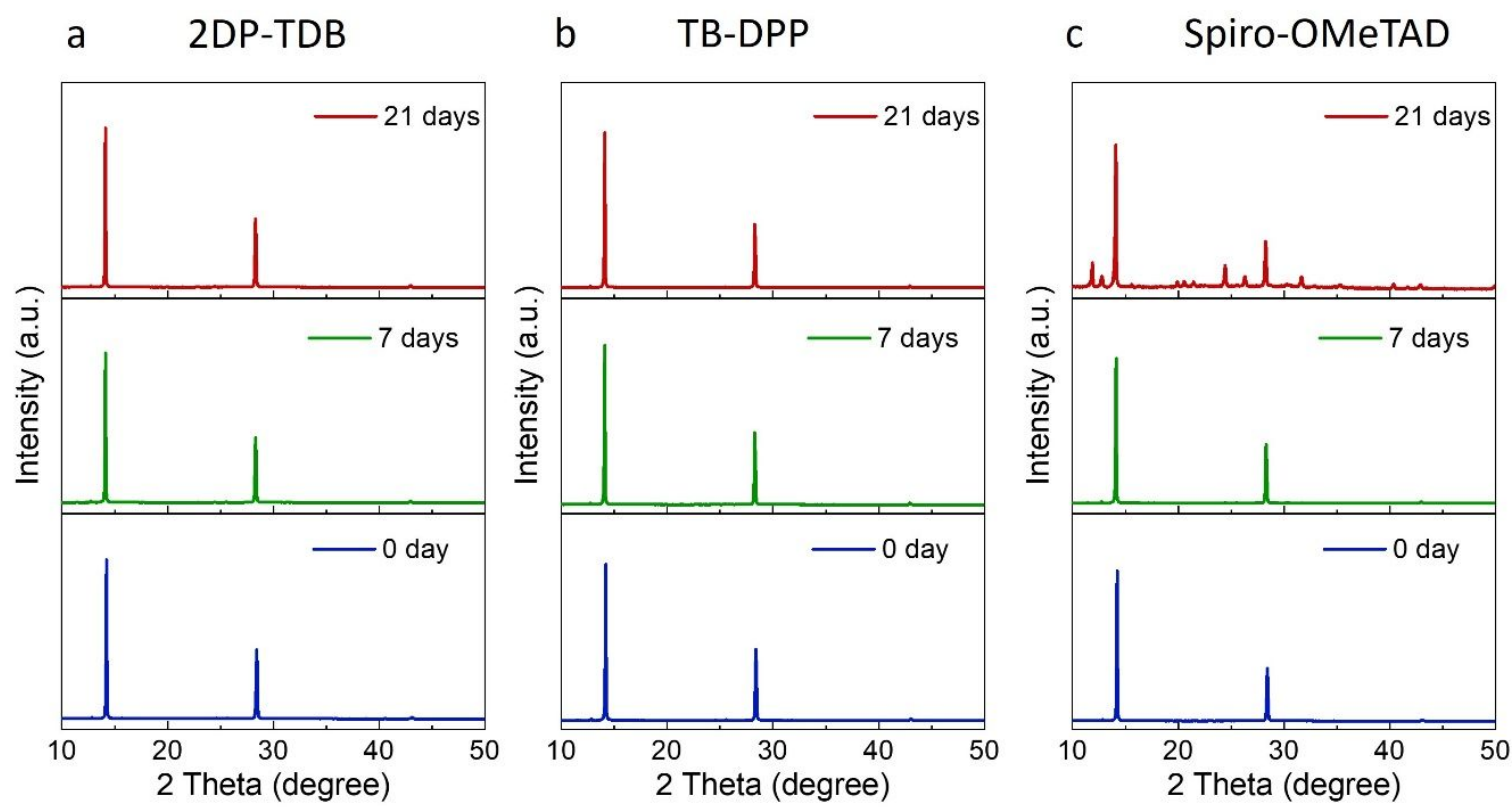

Figure S24. XRD results of perovskite films covered with (a) 2DP-TDB, (b) TP-DPP and (c) Spiro-OMeTAD as HTMs measured at regular intervals under ambient conditions with a relative humidity of $\sim 30 \%$ for 7 days and relative humidity of $\sim 80 \%$ for subsequent 14 days. 

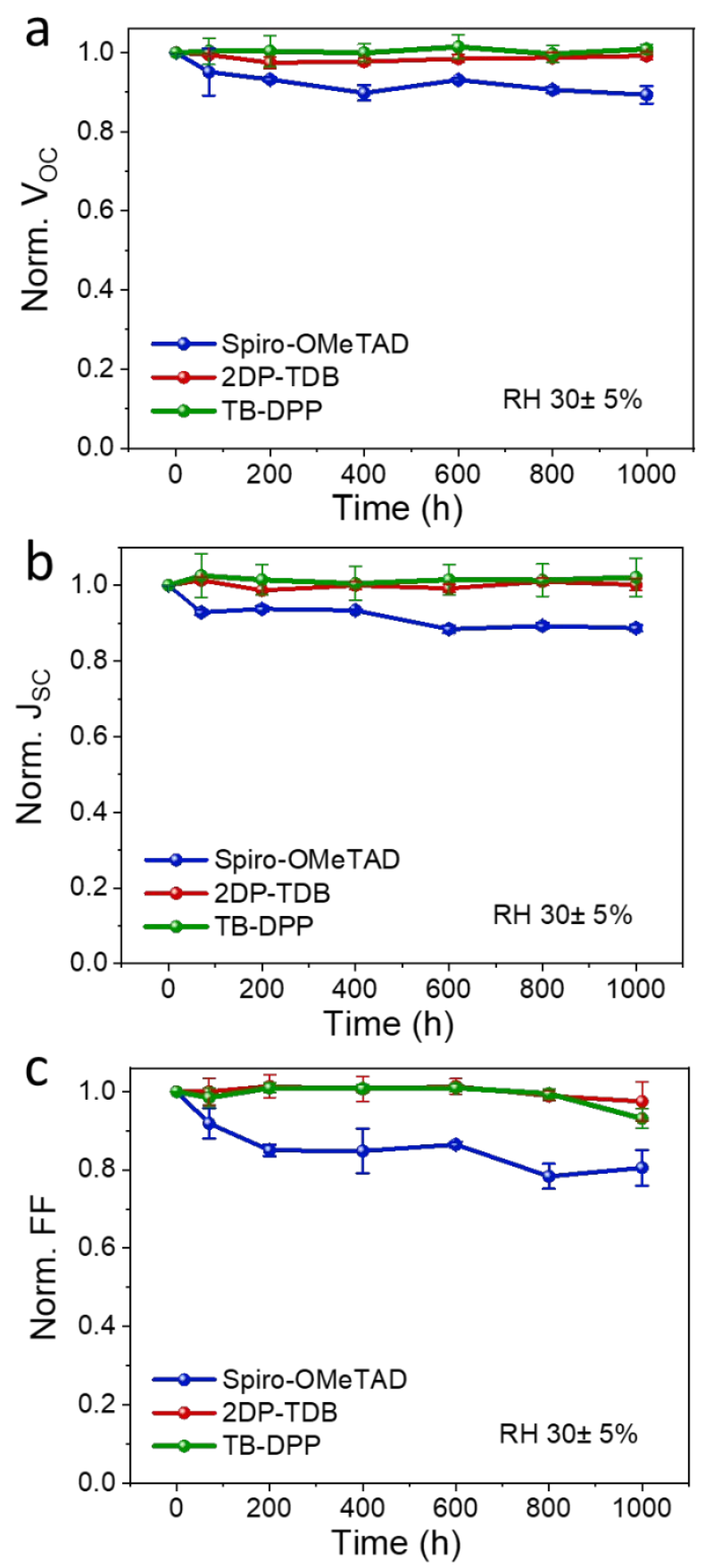

Figure S25. Device ambient stability. Normalized photovoltaic parameters of (a) PCE, (b) $V_{O C}$, (c) FF and (d) $\mathrm{J}_{\mathrm{SC}}$ as a function of time for unencapsulated devices with different HTMs stored in air at room temperature (RT) with relative humidity $(\mathrm{RH})$ of $30 \pm 5 \%$. 

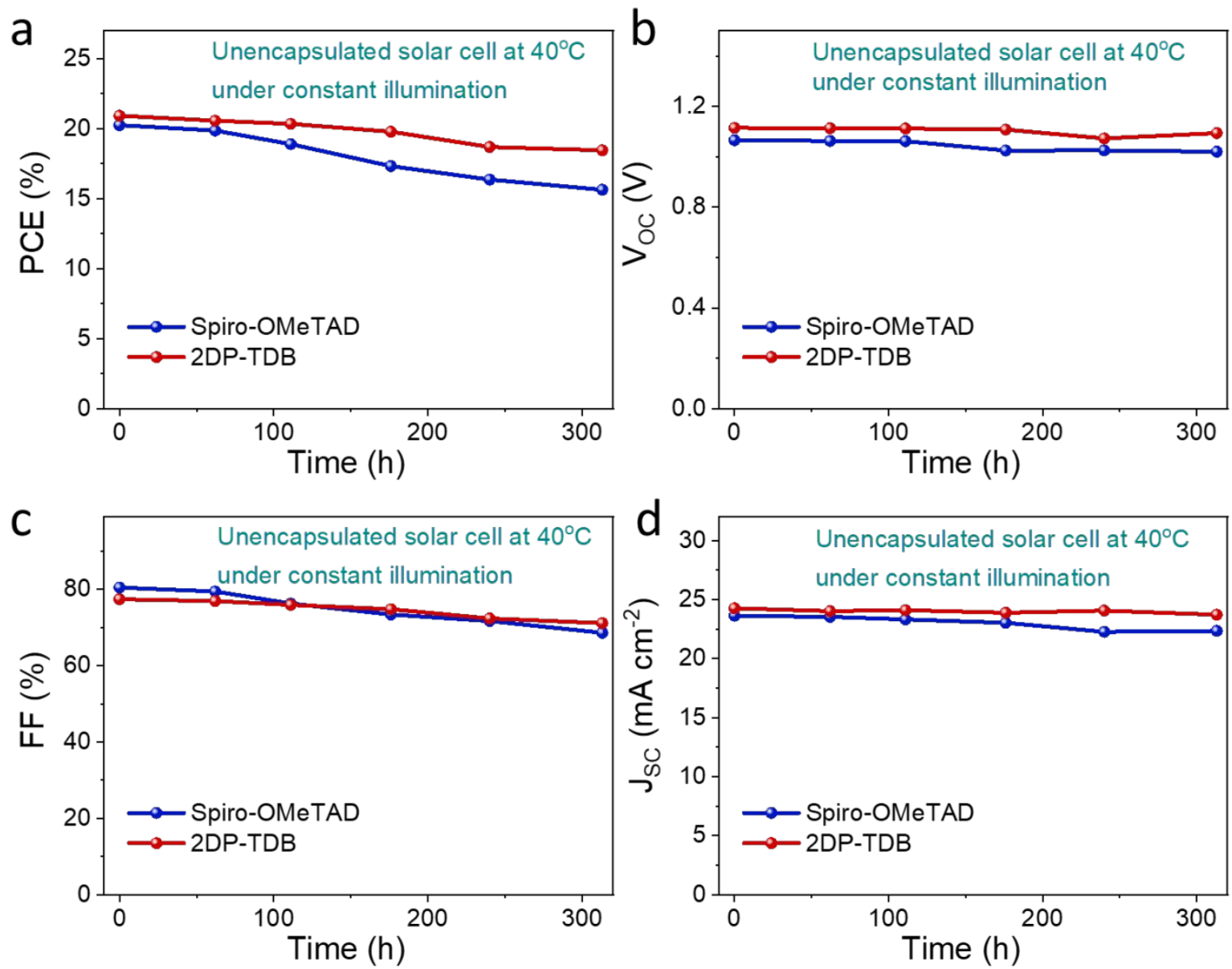

Figure S26. Device light stability. Photovoltaic parameters of (a) PCE, (b) $\mathrm{V}_{\mathrm{OC}}$, (c) FF and (d) $\mathrm{J}_{\mathrm{SC}}$ as a function of time for unencapsulated devices with different HTMs stored in a nitrogen atmosphere at $40^{\circ} \mathrm{C}$ under continuous light soaking (1 sun illumination, white light-emitting diode (LED), $100 \mathrm{~mW} \mathrm{~cm}^{-2}$ ). 

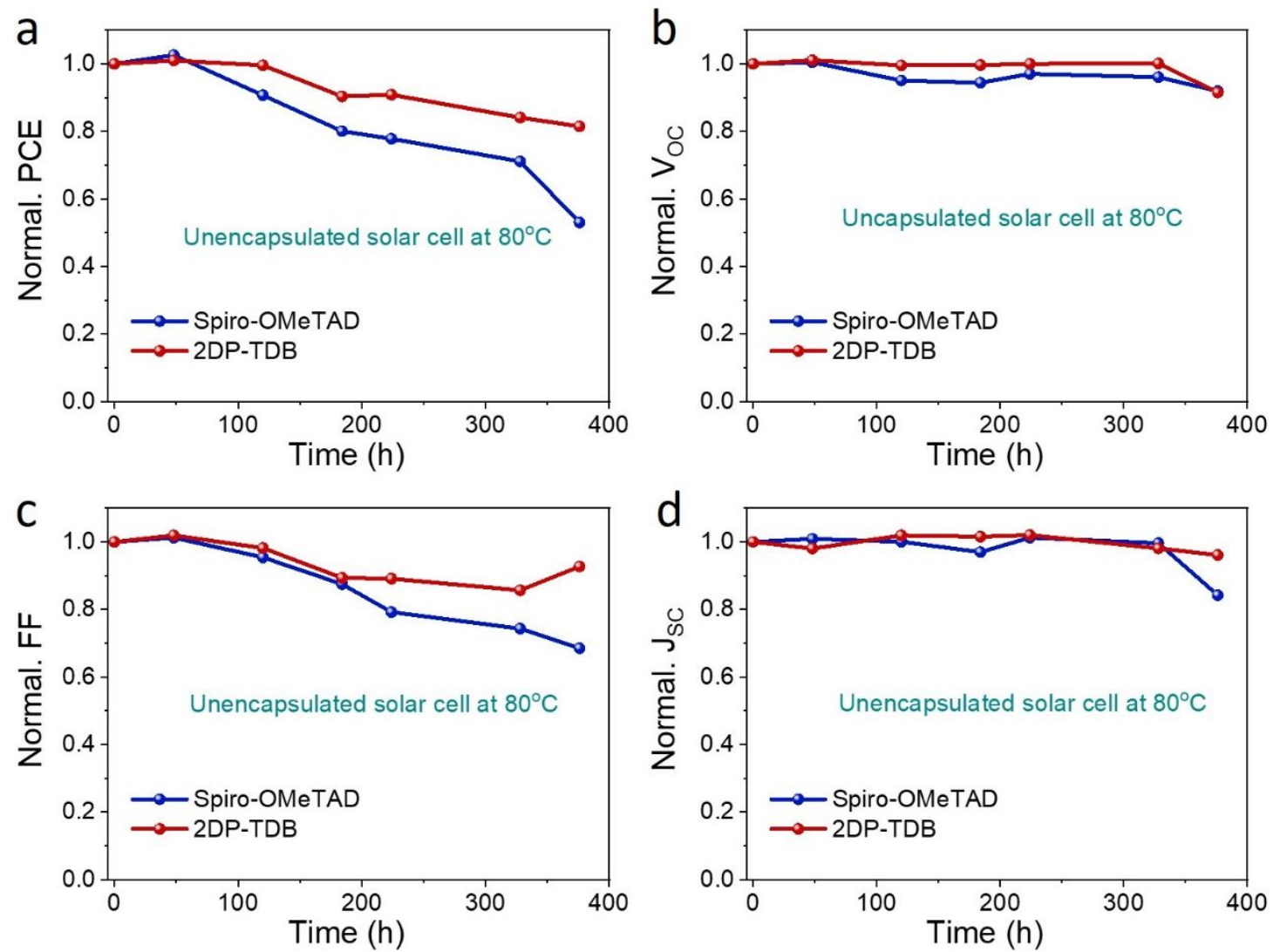

Figure S27. Device thermal stability. Normalized photovoltaic parameters of (a) PCE, (b) $V_{O C}$, (c) FF and (d) $\mathrm{J}_{\mathrm{SC}}$ as a function of time for unencapsulated devices with different HTMs stored in a nitrogen atmosphere at $80^{\circ} \mathrm{C}$ in dark. 

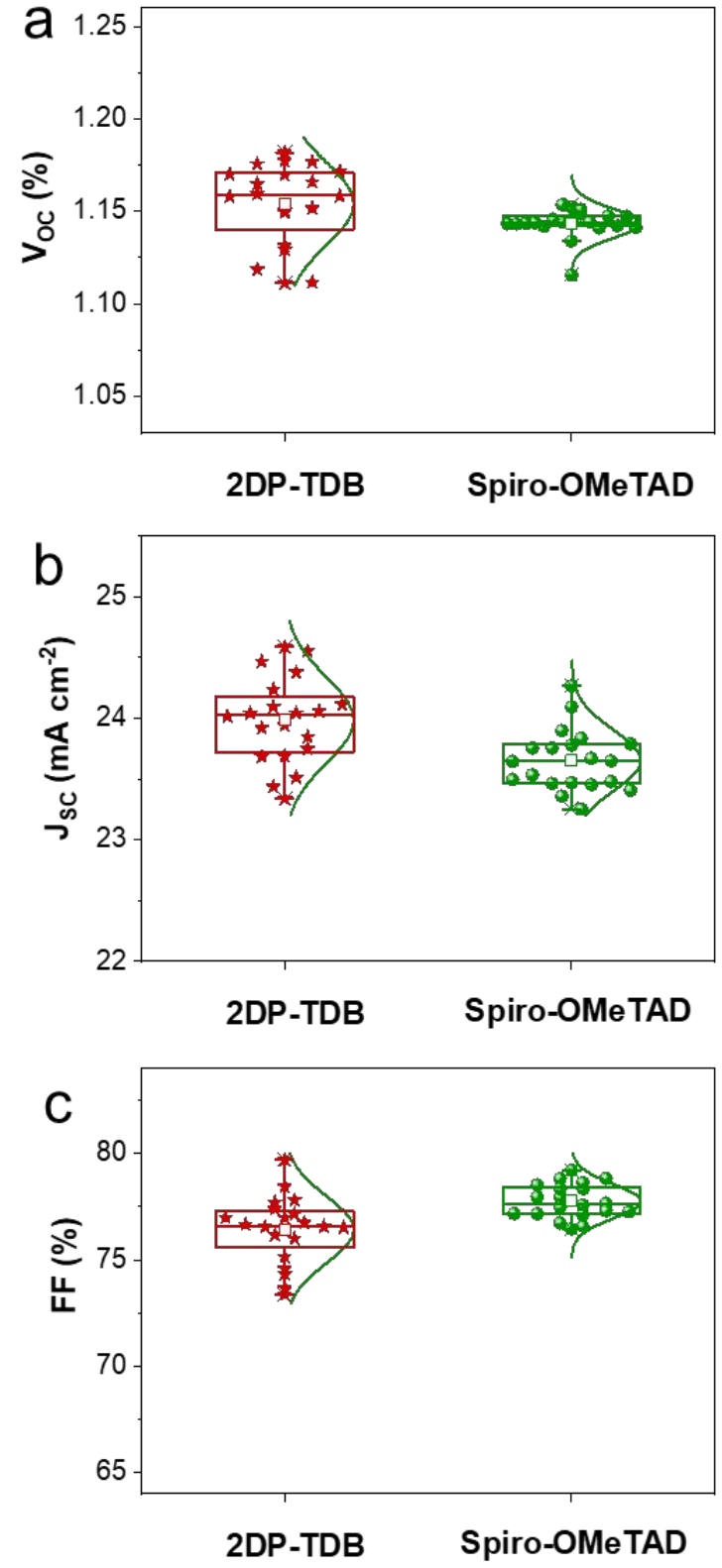

Figure S28. Photovoltaic performance variations for 20 individual solar cells with the pFPhFACl optimized perovskite layer based on dopant-free 2D HTMs and doped SpiroOMeTAD. 


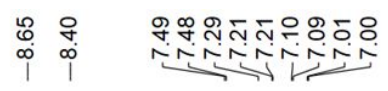

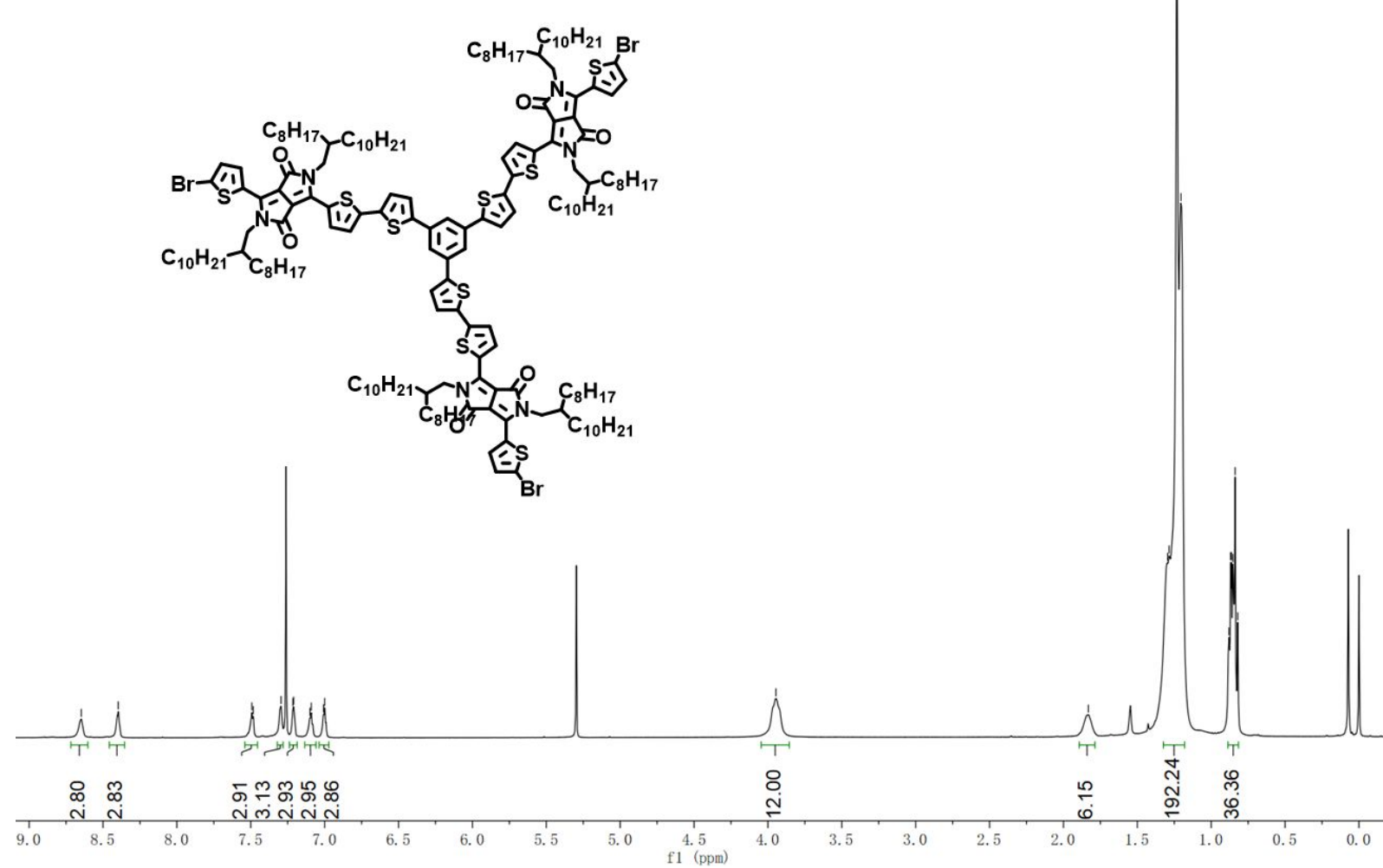

Figure S29. ${ }^{1} \mathrm{H}$ NMR spectrum of polymer monomer TB-DPP-Br in $\mathrm{CDCl}_{3}$ 

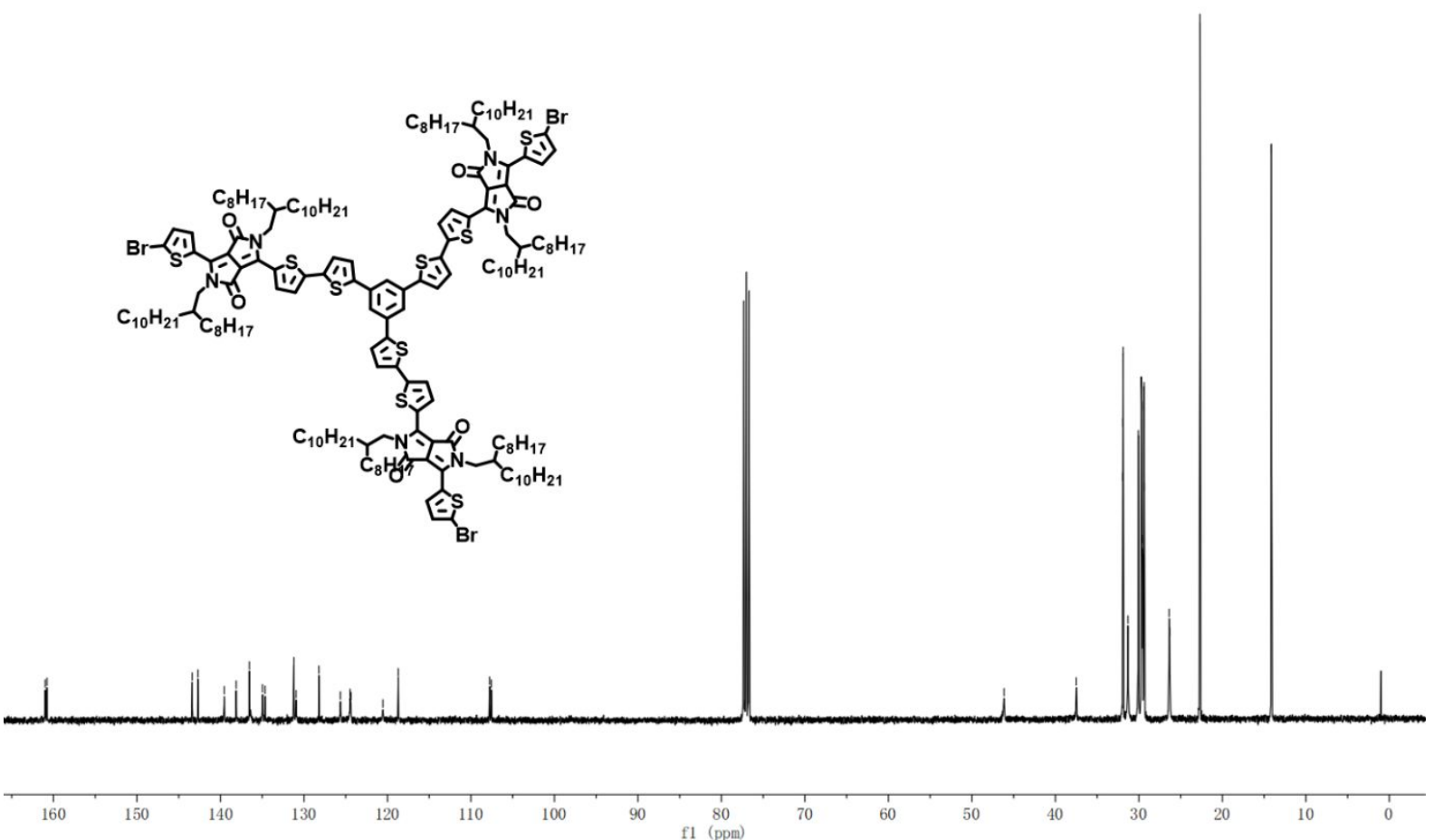

Figure S30. ${ }^{13} \mathrm{C}$ NMR spectrum of polymer monomer TB-DPP-Br. 
5. Supporting Tables.

Table S1. Elemental analysis results of 2DP-TDB.

\begin{tabular}{lllll}
\hline & $\mathrm{C} \%$ & $\mathrm{H} \%$ & $\mathrm{~N} \%$ & $\mathrm{~S} \%$ \\
\hline Calcd. & 73.90 & 9.15 & 2.15 & 12.34 \\
Found & 71.15 & 7.73 & 2.42 & 11.46 \\
\hline
\end{tabular}

Table S2. The solubility of 2DP-TDB in various solvents

\begin{tabular}{l|lll}
\hline \multirow{2}{*}{ 2DP-TDB } & \multicolumn{3}{|l}{ Solubility $\left(\mathrm{mg} \mathrm{mL}^{-1}\right)$} \\
\cline { 2 - 4 } & CF & CB & DCB \\
\hline $\mathrm{Mn}=119 \mathrm{~K}, \mathrm{PDI}=2.10$ & 11 & 17 & 12 \\
\hline
\end{tabular}

Table S3. Optical and electrochemical properties of HTMs.

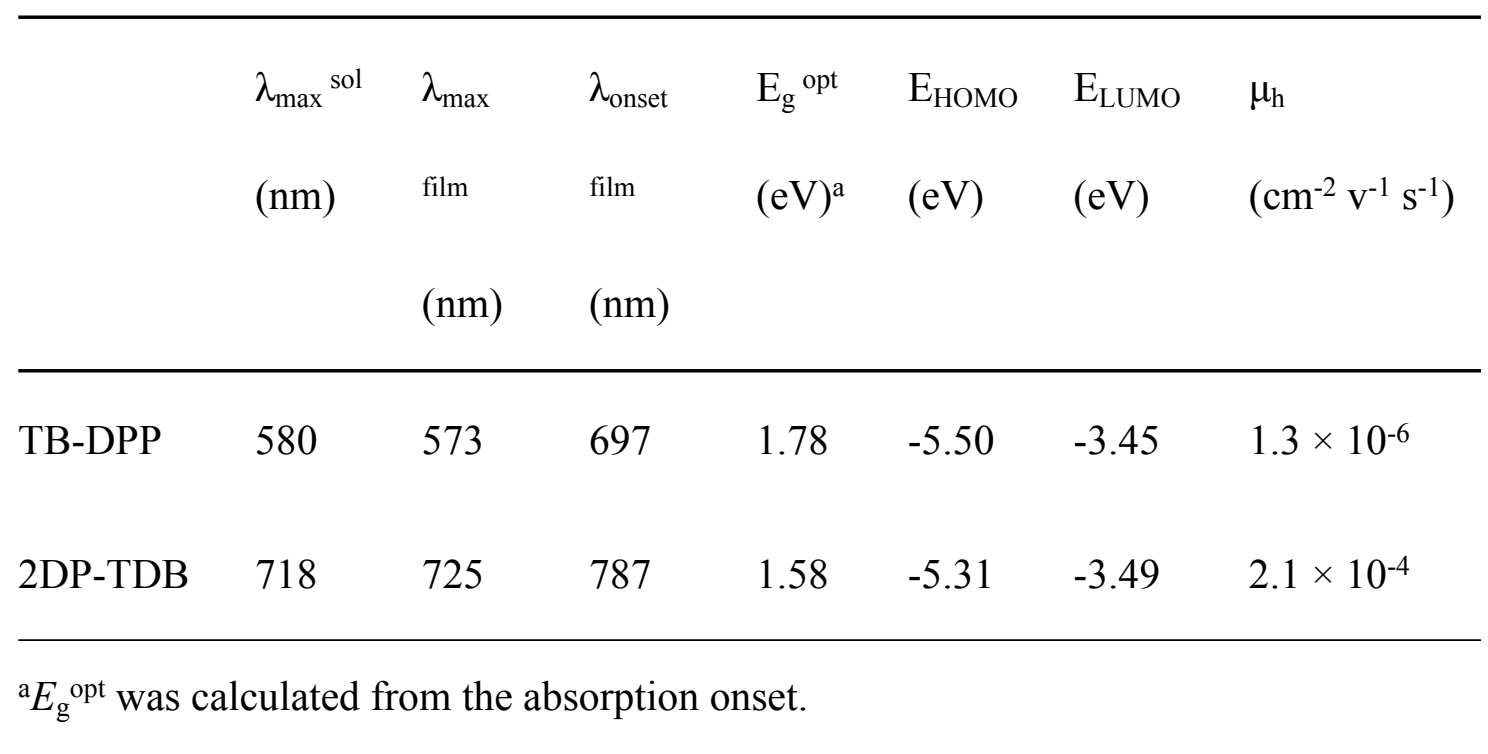


Table S4. The J-V performance of PSCs manufactured with 2DP-TDB solutions from different precursor concentrations with spin coating speed of $1500 \mathrm{rpm}$.

\begin{tabular}{ccccc}
\hline Concentration $\left(\mathrm{mg} \mathrm{mL}^{-1}\right)$ & Voc $(\mathrm{V})$ & $\mathrm{Jsc}\left(\mathrm{mA} \mathrm{cm}^{-2}\right)$ & $\mathrm{FF}(\%)$ & PCE (\%) \\
\hline 5 & 1.14 & 24.35 & 74.5 & 20.68 \\
7 & 1.16 & 23.80 & 75.7 & 20.90 \\
9 & 1.15 & 23.79 & 75.7 & 20.78 \\
11 & 1.15 & 23.58 & 70.2 & 19.04 \\
\hline
\end{tabular}

Table S5. The J-V performance of PSCs manufactured with 2DP-TDB obtained from $7 \mathrm{mg}$ $\mathrm{mL}^{-1}$ chloroform with different spin coating speed.

\begin{tabular}{ccccc}
\hline Spin coating speed (rpm) & Voc (V) & Jsc (mA cm $\left.{ }^{-2}\right)$ & FF (\%) & PCE (\%) \\
\hline 1000 & 1.14 & 23.97 & 74.5 & 20.36 \\
1500 & 1.15 & 24.48 & 75.5 & 21.25 \\
2000 & 1.16 & 24.13 & 76.9 & 21.53 \\
2500 & 1.14 & 24.06 & 77.0 & 21.12 \\
\hline
\end{tabular}


Table S6. The J-V performance of PSCs manufactured with TB-DPP solutions from different precursor concentrations with spin coating speed of $6000 \mathrm{rpm}$.

\begin{tabular}{ccccc}
\hline Concentration $\left(\mathrm{mg} \mathrm{mL}^{-1}\right)$ & Voc $(\mathrm{V})$ & $\mathrm{Jsc}\left(\mathrm{mA} \mathrm{cm}^{-2}\right)$ & $\mathrm{FF}(\%)$ & PCE (\%) \\
\hline 12 & 1.02 & 17.50 & 48.7 & 8.69 \\
14 & 1.00 & 18.59 & 51.8 & 9.63 \\
16 & 1.01 & 19.96 & 42.8 & 8.63 \\
18 & 1.00 & 19.12 & 37.3 & 7.13 \\
\hline
\end{tabular}

Table S7. The J-V performance of PSCs manufactured with TB-DPP obtained from $14 \mathrm{mg}$ $\mathrm{mL}^{-1}$ chloroform with different spin coating speed.

\begin{tabular}{ccccc}
\hline Spin coating speed (rpm) & Voc (V) & Jsc (mA cm $\left.{ }^{-2}\right)$ & FF (\%) & PCE (\%) \\
\hline 4000 & 0.98 & 19.13 & 52.9 & 9.92 \\
6000 & 1.04 & 20.50 & 48.1 & 10.25 \\
8000 & 1.03 & 18.97 & 59.4 & 11.61 \\
10000 & 1.05 & 17.56 & 58.8 & 10.84 \\
\hline
\end{tabular}


Table S8. Summary of photovoltaic parameters of devices with different HTMs under different scan directions.

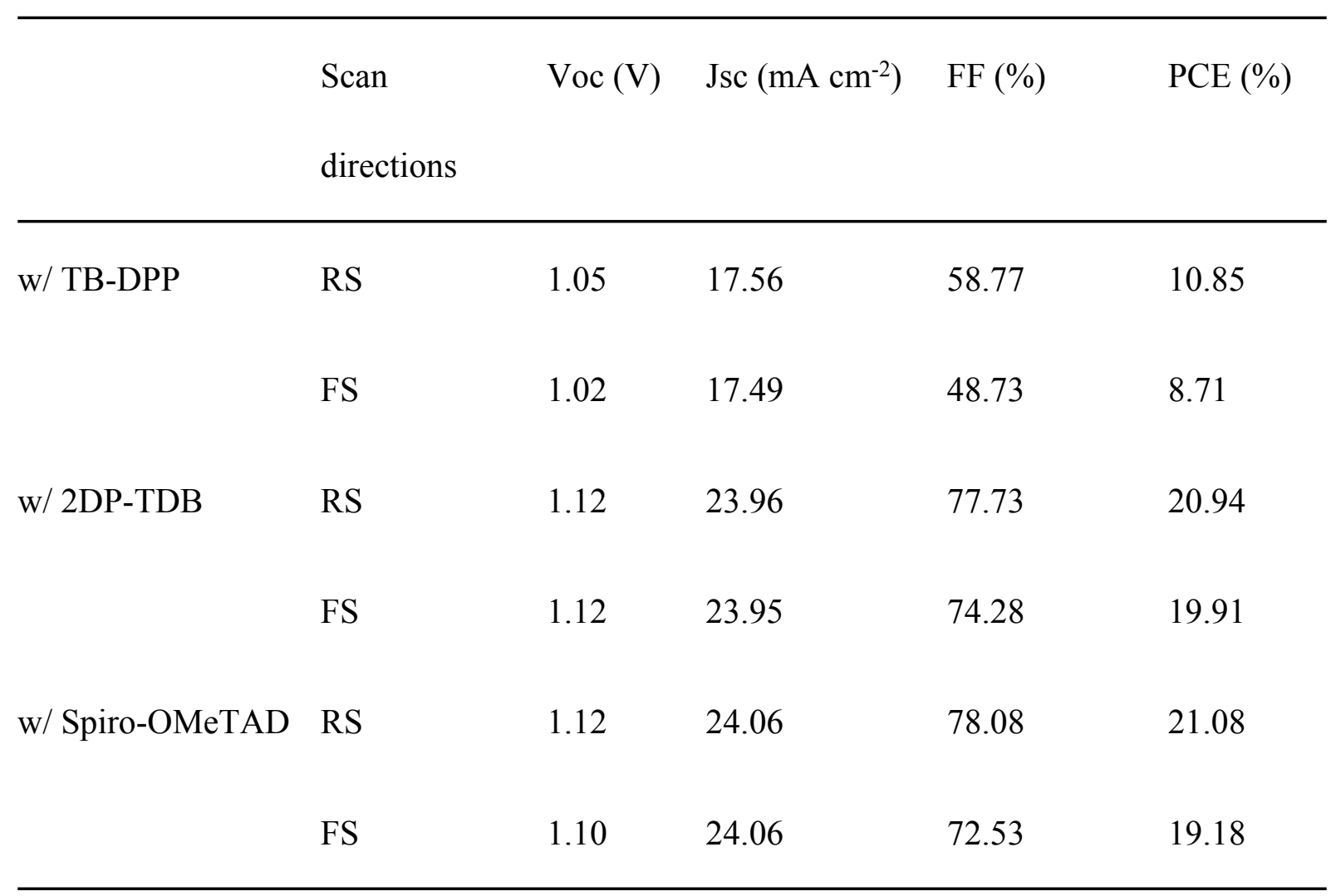

Table S9. Hole mobility of 2DP-TDB compared with common HTM such as Spiro-OMeTAD, PTAA, P3HT.

\begin{tabular}{llc}
\hline Different HTM & Dopant-free mobility & Doped mobility \\
& $\left(\mathrm{cm}^{2} \mathrm{v}^{-1} \mathrm{~s}^{-1}\right)$ & $\left(\mathrm{cm}^{2} \mathrm{v}^{-1} \mathrm{~s}^{-1}\right)$ \\
\hline Spiro-OMeTAD $^{[5,6]}$ & $9.04 \times 10^{-6}$ & $4.65 \times 10^{-4}$ \\
PTAA $^{[7]}$ & $\sim 1 \times 10^{-2}$ to $\sim 1 \times 10^{-3}$ &
\end{tabular}




$\begin{array}{ll}\mathrm{P} \mathrm{HT}^{[8]} & \sim 10^{-5} \\ \text { 2DP-TDB } & 2 \times 10^{-4}\end{array}$

Table S10. Photovoltaic parameters of unencapsulated doped Spiro-OMeTAD-based PSC devices stored in a nitrogen atmosphere at $40^{\circ} \mathrm{C}$ under continuous one-sun illumination throughout $313 \mathrm{~h}$.

\begin{tabular}{llccc}
\hline & Voc $(\mathrm{V})$ & $\mathrm{Jsc}\left(\mathrm{mA} \mathrm{cm}^{-2}\right)$ & FF $(\%)$ & PCE (\%) \\
\hline As fabricated & 1.07 & 23.62 & 80.47 & 20.26 \\
$62 \mathrm{~h}$ & 1.06 & 23.53 & 79.45 & 19.87 \\
$111 \mathrm{~h}$ & 1.06 & 23.32 & 76.31 & 18.90 \\
$176 \mathrm{~h}$ & 1.02 & 23.0 & 73.42 & 17.32 \\
$240 \mathrm{~h}$ & 1.023 & 22.27 & 71.71 & 16.37 \\
$313 \mathrm{~h}$ & 1.02 & 22.34 & 68.62 & 15.64 \\
\hline
\end{tabular}

Table S11. Photovoltaic parameters of unencapsulated 2DP-TDB-based PSC devices stored in a nitrogen atmosphere at $40^{\circ} \mathrm{C}$ under continuous one-sun illumination throughout $313 \mathrm{~h}$.

\begin{tabular}{lcccc}
\hline & Voc $(\mathrm{V})$ & $\mathrm{Jsc}\left(\mathrm{mA} \mathrm{cm}^{-2}\right)$ & FF (\%) & PCE (\%) \\
\hline As fabricated & 1.11 & 24.26 & 77.42 & 20.93 \\
$62 \mathrm{~h}$ & 1.11 & 24.02 & 76.96 & 20.58 \\
$111 \mathrm{~h}$ & 1.11 & 24.09 & 75.94 & 20.35 \\
$176 \mathrm{~h}$ & 1.10 & 23.88 & 74.79 & 19.79 \\
$240 \mathrm{~h}$ & 1.07 & 24.06 & 72.40 & 18.69
\end{tabular}


18.46 
Table S12. Detailed parameters for 20 devices with the optimized perovskite layer based on dopant-free 2D HTMs and doped Spiro-OMeTAD.

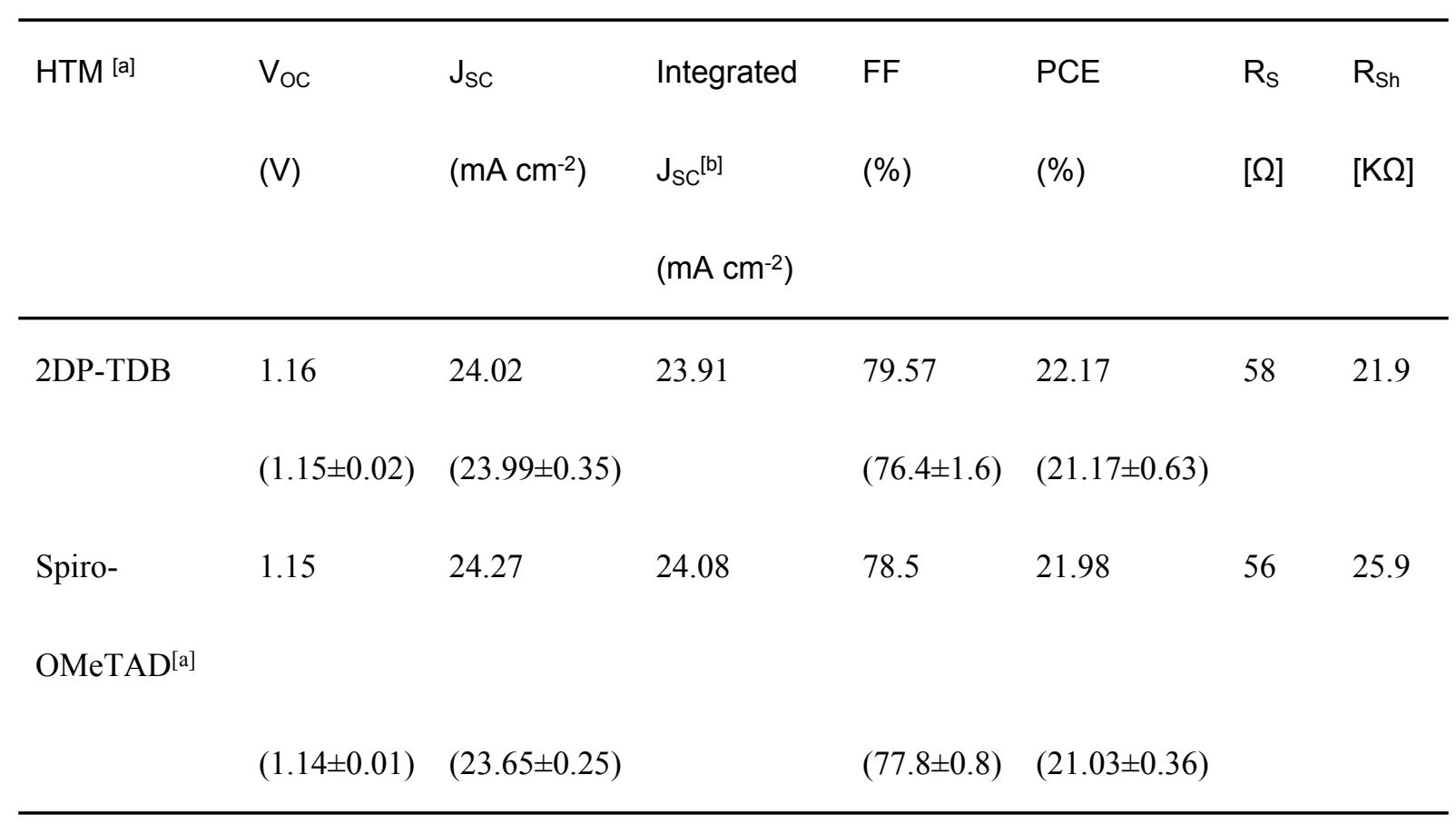

${ }^{\text {[a] }}$ doped with LiTFSI and 4-tert-butylpyridine. ${ }^{[\mathrm{b}]}$ Calculated from EQE curves.

Table S13. TRPL parameters of perovskite films without and with HTMs

\begin{tabular}{lll}
\hline Samples & $\boldsymbol{\tau}_{\mathbf{1}}$ & $\boldsymbol{\tau}_{\mathbf{2}}$ \\
\hline w/o HTM & $123 \mathrm{~ns}$ & $828 \mathrm{~ns}$ \\
2DP-TDB & $8 \mathrm{~ns}$ & 82 \\
TB-DPP & $15 \mathrm{~ns}$ & 84 \\
\hline
\end{tabular}


Reference

[1] L. Dou, J. Gao, E. Richard, J. You, C.-C. Chen, K. C. Cha, Y. He, G. Li, Y. Yang, J. Am. Chem. Soc. 2012, 134, 10071.

[2] K. Zhang, P. Wucher, T. Marszalek, M. Babics, A. Ringk, P. W. M. Blom, P. M.

Beaujuge, W. Pisula, Chem. Mater. 2018, 30, 5032.

[3] Y. Li, Y. Cao, J. Gao, D. Wang, G. Yu, A. J. Heeger, Synth. Met. 1999, 99, 243.

[4] Y. Liu, J. Zhou, X. Wan, Y. Chen, Tetrahedron 2009, 65, 5209

[5] J. Qiu, H. Liu, X. Li, S. Wang, F. Zhang, Solar RRL 2019, 3, 1900202.

[6] R. Azmi, S. Y. Nam, S. Sinaga, Z. A. Akbar, C.-L. Lee, S. C. Yoon, I. H. Jung, S.-Y. Jang, Nano Energy 2018, 44, 191.

[7] J. H. Heo, S. H. Im, J. H. Noh, T. N. Mandal, C.-S. Lim, J. A. Chang, Y. H. Lee, H.-j. Kim, A. Sarkar, M. K. Nazeeruddin, M. Grätzel, S. I. Seok, Nat. Photonics 2013, 7, 486.

[8] E. H. Jung, N. J. Jeon, E. Y. Park, C. S. Moon, T. J. Shin, T.-Y. Yang, J. H. Noh, J. Seo, Nature 2019, 567, 511. 